Bull. Fac . Agric., Cairo Univ. , 69: 223-241 (2018).

\title{
ECONOMIC ANALYSIS OF PRODUCTION AND CONSUMPTION OF OIL CROPS IN EGYPT
}

(Received:31.12.2018)

\author{
By \\ M.M.H. Mileek \\ Agricultural Economics Research Department, Agricultural Economics Research Institute, \\ Agricultural Research Center, Giza, Egypt
}

\begin{abstract}
Food oil crops are the most important strategic commodities for humans, which supplies energy and fats. There are major crops indulged in the production of oil such as soybean, peanuts, sesame and sunflower. Other crops which produce oil not as the main product are fiber crops such as cotton and Flax seed. Also crops such as grain maize can be squeezed to extract the oil from the embryo of corn grain,and from some fruits such as olive and palm There are a deficit in vegetables food oil in Egypt estimated 999 thousand tons. The self-sufficiency rate is about $43 \%$ as an average for the period 2013-2015. The present research aimed to study the current situation of the production and consumption of oil crops in Egypt by analyzing the economic indicators of the vegetable oil food crops, determine the size of the food gap in order to reduce it, estimate the average per capita value of vegetable oil, and determine the quantity and value of the losses of oil crops in Egypt. In order to achieve high levels of self-sufficiency, as well as study and analyze of the most important economic factors of specific effects to individual consumption of vegetable oil in Egypt, and estimate the contribution of production to cover domestic consumption during the average period (2005-2015). The results showed that oil crops contribute a small percentage of the value of agricultural production, representing about $0.81 \%$ as an average for the period 2005-2013. The following crops achieved the highest percentage of total benefits to costs such as peanuts, sesame and Maize which represent $2.51 \% .1 .78 \%$ and $1.70 \%$, respectively. the profitability of the pound spent for these crops was $1.51 \%, 78 \%, 62 \%$, respectively.The study recommends that the government should cooperate with the private sector in establishing more factories for the extraction of oil to increase oil production and reconsider subsidizing agricultural production inputs requirements to encourage the farmer to grow various oil crops.
\end{abstract}

Key words: Production, consumption, vegetable oils, benefit to cost ratio , oil gap food,selfsufficiency percentage, consumption function .

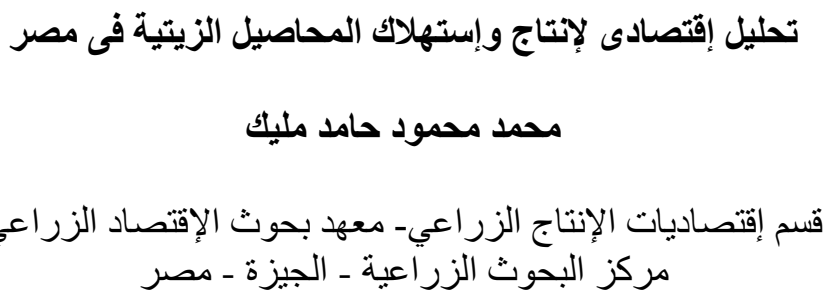

ملخص أبحنة

تعد الزيوت النباتية الغذائية من السلع الاستر اتيجية الهامة للإنسان حيث تمده بالطاقة والدهون. وتتنوع

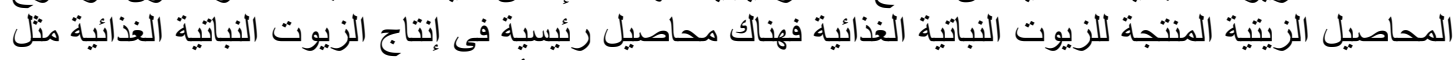

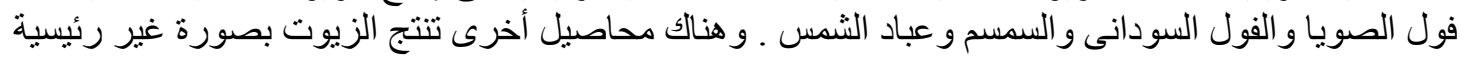


كمحاصيل الألياف كبذرة القطن وبذرة الكتان. و هناك محاصيل أخرى للحبوب ينم عصر ها واستخلاص الزيت

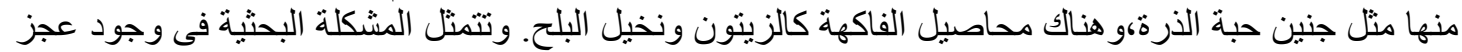

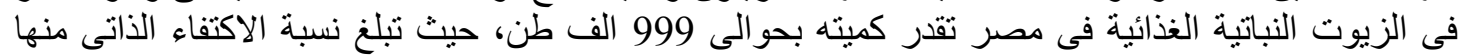

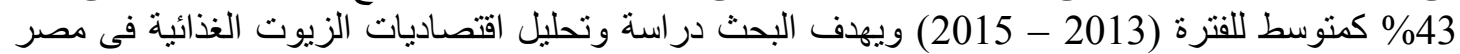

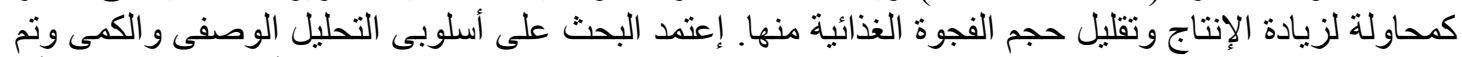

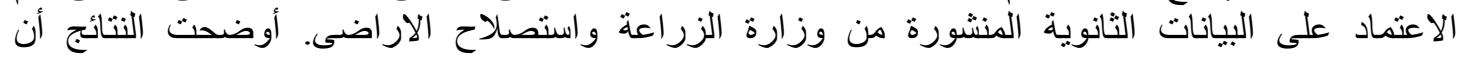

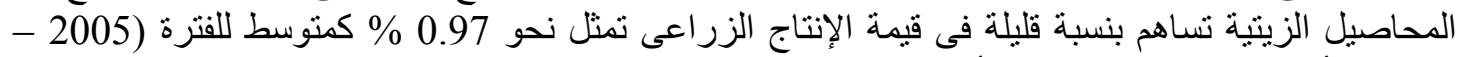

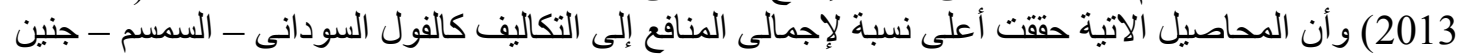

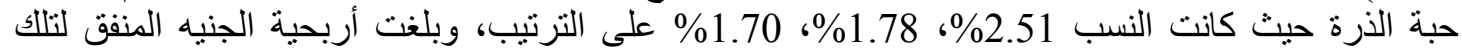

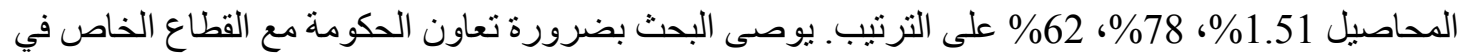

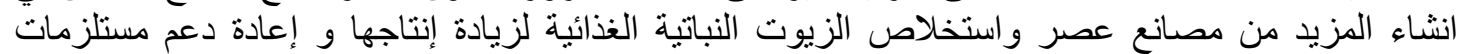

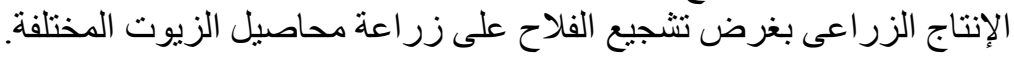

وتحليل أهم العوامل الإقتصادية المحددة للإستهلاك

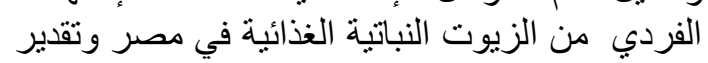
نسبة مساهمة الإنتاج لتغطية الإستهلاك النئ المحلي خلال منوسط الفترة 2005- 2015 م الإنتاج

\section{3. الطريقة البحثية ومصادر البيانات}

إعتمد البحث على أسلوب البحة التحليل الوصفى البيان

و الكمى في تحليل و عرض البه البيانات المتحصل علئل الئها، حيث تم استخدام المنوسطات و النسب المئوية وكذللك النيات معادلات الاتجاه الزمنى العام. كما تم استخدام أسلوب العزب

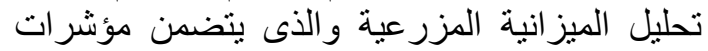
الكفاءة الاقتصادية مثل التكاليف الكلية و الاير اد الكلى الكئل

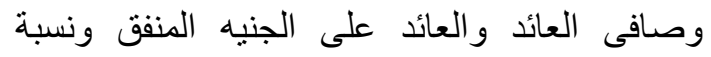

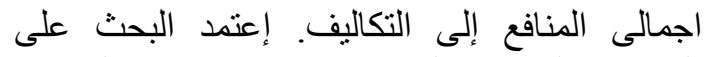

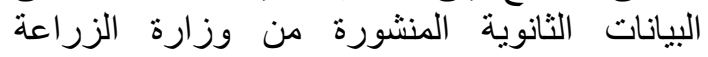

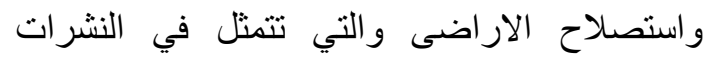

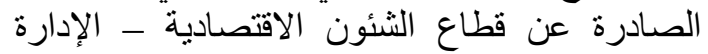

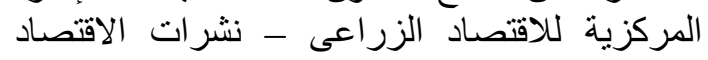

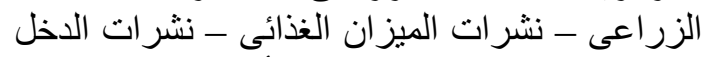

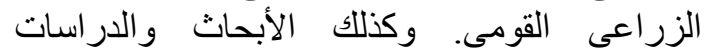
والرسائل و المراجع العلمية العربية والأجنبية ذات التات

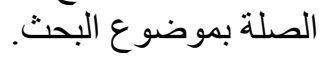

\section{4. نتائج البحث}

يوضح جدول (1) تطور القيمة النقدية للبذور

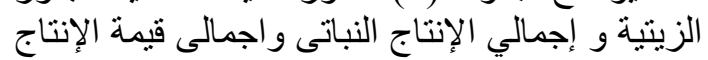

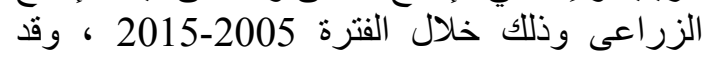

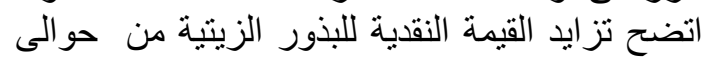
771.47 مليون جنيه في 2710.99

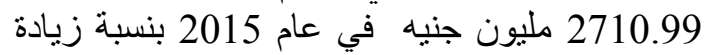

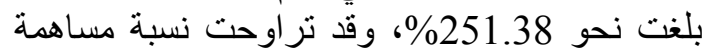
قيمة البذور الزينية في قيمة الإنتاج النباتى وقيمة فئة

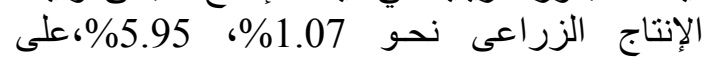

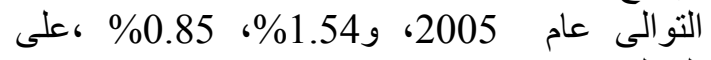
التو الى عام 2015.

\section{1 المقدمة}

تسعى الدولة إلى زيادة الإنتاج من كافة السلع

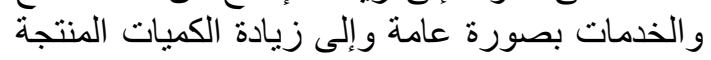

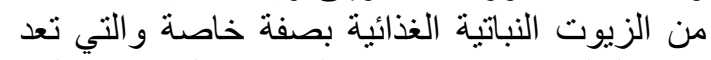

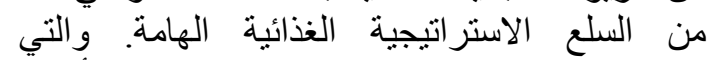
تعتبرضرورية في غذاء الإنسان وكذللك لها أهية أهية

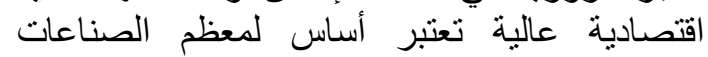

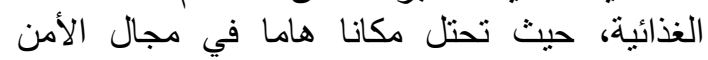

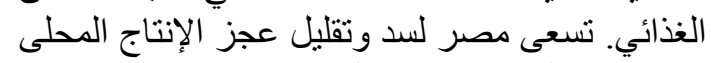

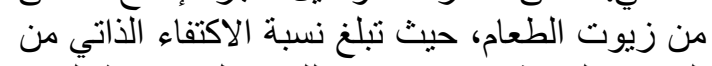

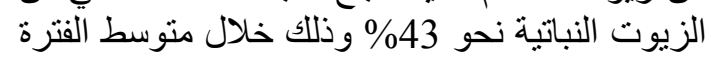

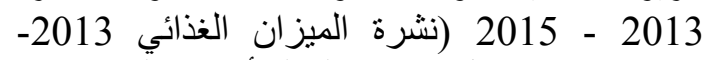

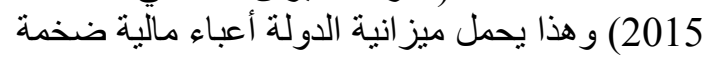

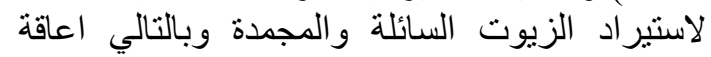

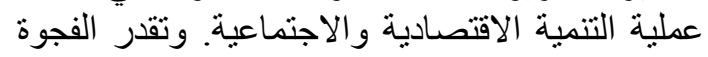

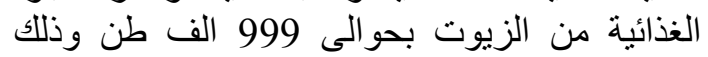
خلال منوسط نفس الفترة السابقة.

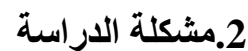

على الرغم من أهمية الزيوت النباتية النية الغذائية

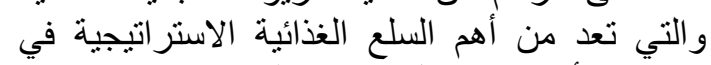

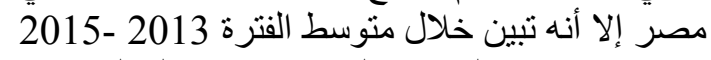

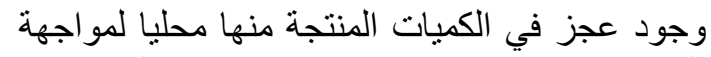

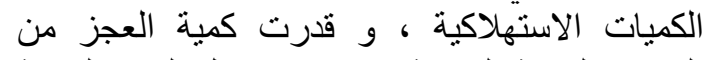
الزيوت النباتية الغذائية في مصر خلائية فلال الفترة السابقة إلى حو الي 999 الف طن. 1.2. الهـف من البحث

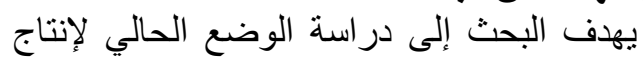

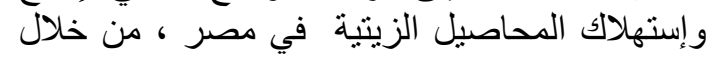

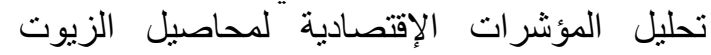

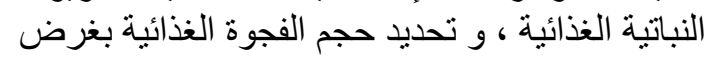

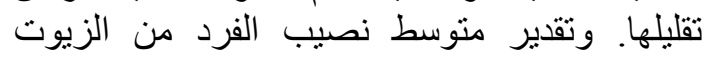
النباتية الغذائية وتحديد كمية وقيمة النية الفاقد من الزية

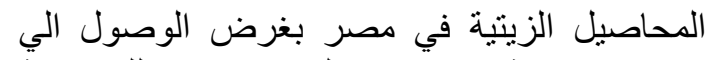

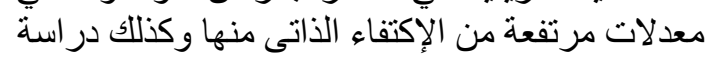


جدول (1): تطور قيمة الحبوب والبذور الزيتية والفاقد منها وكلا من قيمة الإنتاج النباتي وقيمة الإنتاج الزراعى خلال الفترة (2005-2015) (القيم بالمليون جنيه)

\begin{tabular}{|c|c|c|c|c|c|c|c|c|c|}
\hline الفاقد من الحبة الإيتية من قيمة & 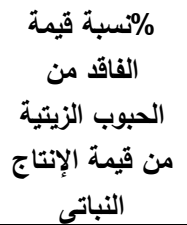 & قيمة الفاقد من الحبوب & كمية الفاقد من النبئية بالبذون & 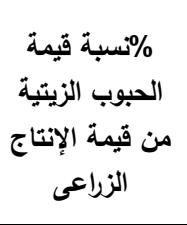 & من الحبوب الزيتية قيمة & قيمة الإنتاج الزراعى & قيمة الإتتاج النباتى & قيمة الحبوب الزيتية & السنوات \\
\hline 0.1 & 0.13 & 96.57 & 88 & 5.95 & 1.07 & 12970.84 & 71910.91 & 771.47 & 2005 \\
\hline 0.3 & 0.48 & 378.14 & 106 & 0.61 & 1.07 & 137419 & 78425 & 839.46 & 2006 \\
\hline 0.3 & 0.54 & 486.30 & 115 & 0.89 & 1.54 & 155945 & 89858 & 1382.88 & 2007 \\
\hline 0.3 & 0.45 & 490.73 & 91 & 0.75 & 1.27 & 185666 & 109792 & 1389.42 & 2008 \\
\hline 0.2 & 0.44 & 473.40 & 84 & 0.97 & 1.68 & 189438 & 108657 & 1829.59 & 2009 \\
\hline 0.35 & 0.62 & 731.21 & 125 & 0.94 & 1.68 & 209354 & 117477 & 1976.56 & 2010 \\
\hline 0.2 & 0.40 & 591.82 & 158 & 0.80 & 1.35 & 249989 & 148501 & 2000.21 & 2011 \\
\hline 0.2 & 0.41 & 656.02 & 152 & 0.81 & 1.34 & 267424 & 160802 & 2162.26 & 2012 \\
\hline 0.3 & 0.58 & 957.15 & 182 & 0.79 & 1.35 & 282434 & 165027 & 2235.11 & 2013 \\
\hline 0.5 & 0.89 & 1517.09 & 162 & 0.77 & 1.38 & 305414 & 170953 & 2361.73 & 2014 \\
\hline 0.5 & 0.90 & 1586.06 & 188 & 0.85 & 1.54 & 318332 & 175517 & 2710.99 & 2015 \\
\hline * * 0.3 & * * 0.5 & 724.04 & 131.91 & $* * 0.97$ & $* * 1.37$ & 220762.3 & 126992.3 & 1787.24 & المتوسط \\
\hline
\end{tabular}

(1) وزارة الزراعة وإستصلاح الأراضي - قطاع الثئون الإقصادية- الإدارة المركزية للإقتصاد الزراعي - نشرات الدخل الزراعي القومي - أعداد مختلفة - نشرات الميزان

الغذائي - أعداد مختلفة. 


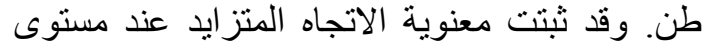
0.05 و ويرجع تز ايد اتجاه الإنتاج الكلى إلى التزايد اليد

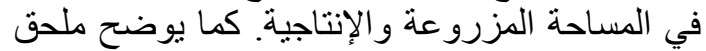

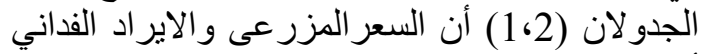

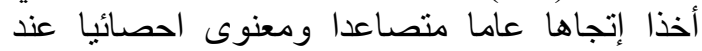

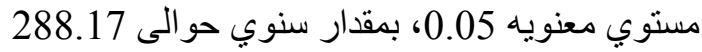

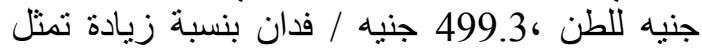

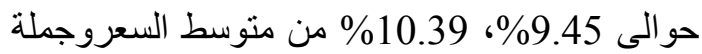

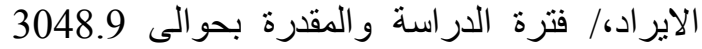

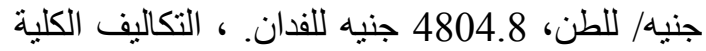

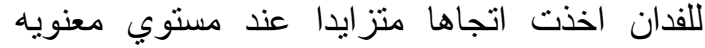
0.05، بمقدار 267.17 جنيه للفدان سنويا بنسبة الفية زيادة قدرت بنحو 9.02\% من منوسط الفترة و البالغة

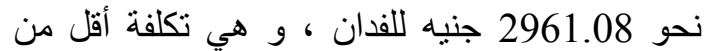
تكلفة الفرصة البديلة للمحاصيل الصيفية المنافسة،

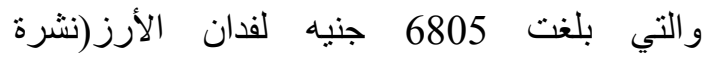

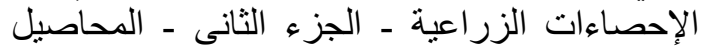
الصيفية و النيلية- 2016)، 3316.96 جنيه لفداع الأن
كما يوضح الجدول أيضا كمية الفاقد من البذور الزينية والتي بلغت في عام 2005 حوالى الى 88 الفي الف الف طن بقيمة 96.57 مليون جنيه تز ايدت عالم عام 2015 إلى لى حوالى 188 الف طن بقيمة 157 بادئ 1586.06 مليون بنسبة

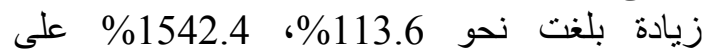
الترتيب. تشير معادلات الاتجاه الزمنى العام بجدول

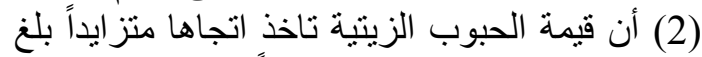

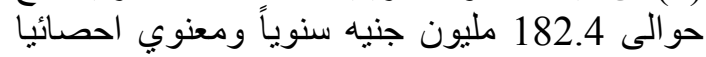

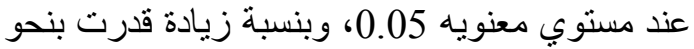

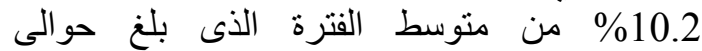
1787.2 مليون جنيه. كما توضح معادلات الفيط الاتجاه

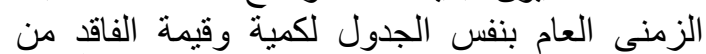

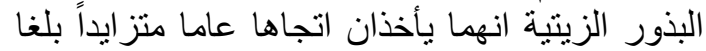

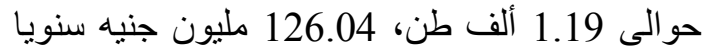

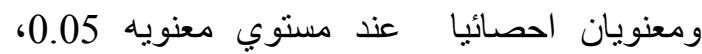

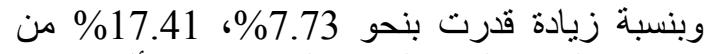
منوسط الفترة الذى بلغ حوالى 131.9 ألف طن طن، 724.04 مليون جنيه.

جدول (2): معادلات الاتجاه الزمنى العام لبعض المتغيرات الاقتصادية خلال القترة (2005-2015).

\begin{tabular}{|c|c|c|c|c|c|c|}
\hline $\begin{array}{c}\text { معدل التغيري السنوي } \\
(\widehat{b} / \bar{x})^{*} \mathbf{1 0 0}\end{array}$ & المتوسط & $\mathbf{F}$ & $\mathbf{R}^{-2}$ & $\mathbf{R}^{2}$ & معادلات الاتجاه الزمنى العام & المتغير التابع \\
\hline 10.2 & 1787.24 & 163.53 & 0.94 & 0.95 & $\begin{array}{c}\text { صه = } 182.36+6930.8 \text { سهـ } \\
\quad(12.79)\end{array}$ & قيمة الحبوب الزيتية \\
\hline 17.41 & 724.04 & 40.53 & 0.80 & 0.82 & 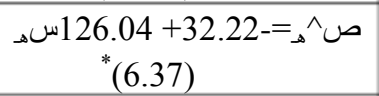 & قالزيتة الفاقد من الحبوب \\
\hline 7.73 & 131.9 & 32.92 & 0.76 & 0.79 & صه = & كمية الفاقد من الحبوب \\
\hline
\end{tabular}

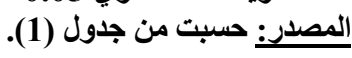

الذرة الثشامية الصيفي ، 5070 جنيه لفدان القطن مما

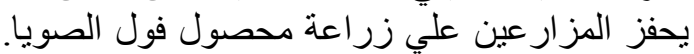

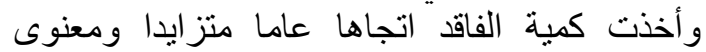

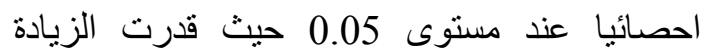
السنوية بمقدار 5.19 الف طن تمثل

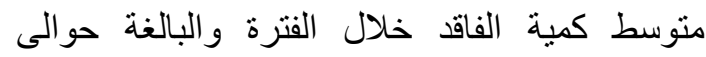
42.23 الف طن. 2.4.محصول الفول السودانى الصيفى:

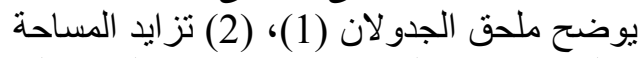

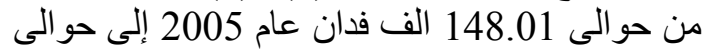
152.9 الف فدان عام 2016 بنسبة زيادة تقدر بنحو الف الفي \%3.30.، و من أهم أصناف التقاوي ذات الإنتاجية

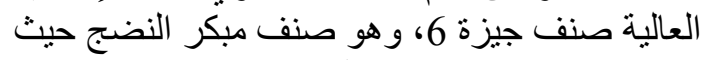

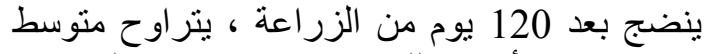

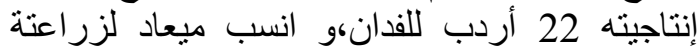
منتصف شهر أبريل (نشرة الإرشاد الزراعي رقم لزران .2016- 1364
1.4. محصول فول الصويا:

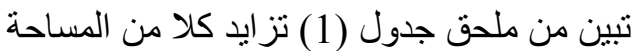
والإنتاجية والإنتاج من من 20.1 الف فن فدان، 1.29

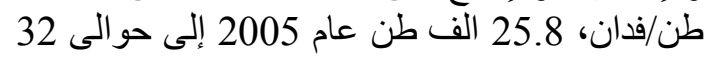
الف فدان، 1.4 طن/فدان، 45.8 الف طن طن خلال عام

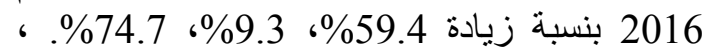
وذللك نتيجة جهود الدولة في تنمية تللك المحاصيل وفي ضوء تنفيذ الإستر اتيجيات المختلفة و المتمنلة في

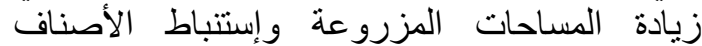
الجديدة من التقاوي ذات الإنتاجية العالية مثل أصناف الإناف

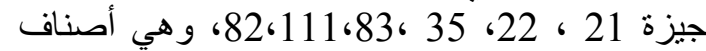

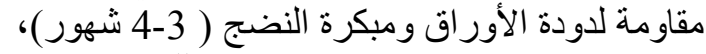
يتراوح متوسط انتاجيتها 1.5 طن للفدان الإن (نشرة

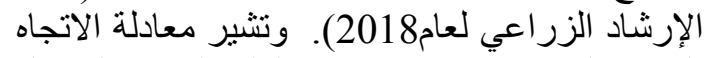

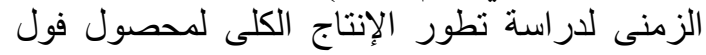
الصويا بملحق جدول(2) إلى تزايد الإنتاج سنويا

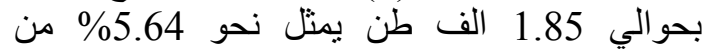
متوسط الفترة للإنتاج الكلى والبالغ نحو 32.8 الف 


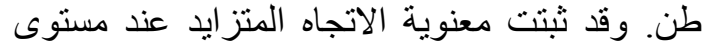
0.05 و ويرجع تز ايد اتجاه الإنتاج الكلى إلى التزايد اليد

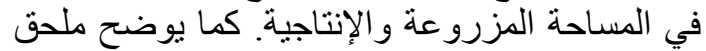

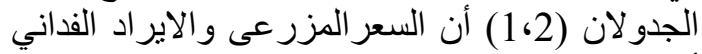

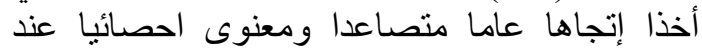

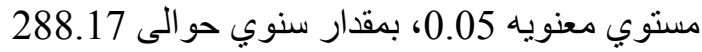

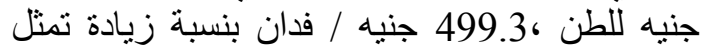

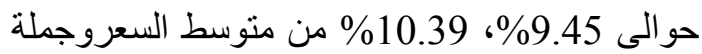

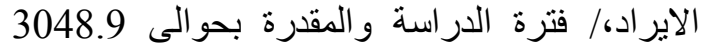

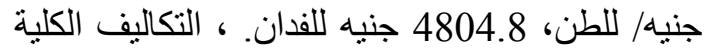

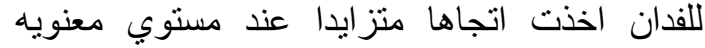
0.05، بمقدار 267.17 جنيه للفدان سنويا بنسبة الفية زيادة قدرت بنحو 9.02\% من منوسط الفترة و البالغة

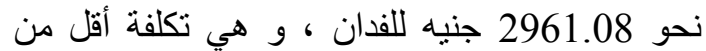
تكلفة الفرصة البديلة للمحاصيل الصيفية المنافسة،

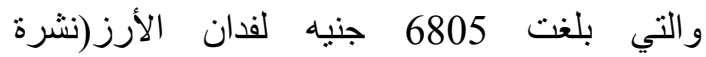

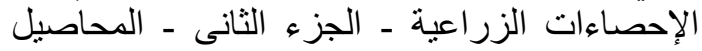
الصيفية و النيلية- 2016)، 3316.96 جنيه لفداع الأن
كما يوضح الجدول أيضا كمية الفاقد من البذور الزينية والتي بلغت في عام 2005 حوالى الى 88 الفي الف الف طن بقيمة 96.57 مليون جنيه تز ايدت عالم عام 2015 إلى لى حوالى 188 الف طن بقيمة 157 بادئ 1586.06 مليون بنسبة

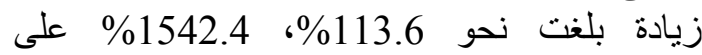
الترتيب. تشير معادلات الاتجاه الزمنى العام بجدول

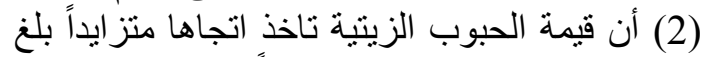

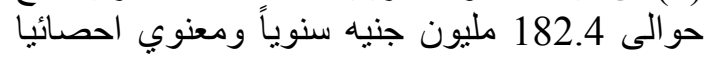

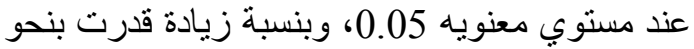

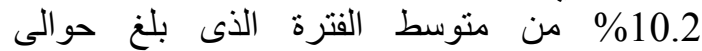
1787.2 مليون جنيه. كما توضح معادلات الفيط الاتجاه

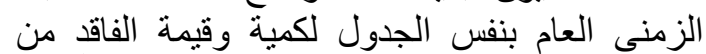

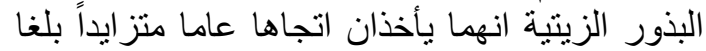

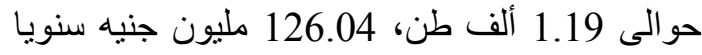

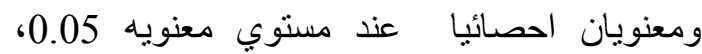

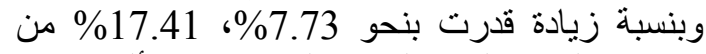
منوسط الفترة الذى بلغ حوالى 131.9 ألف طن طن، 724.04 مليون جنيه.

جدول (2): معادلات الاتجاه الزمنى العام لبعض المتغيرات الاقتصادية خلال القترة (2005-2015).

\begin{tabular}{|c|c|c|c|c|c|c|}
\hline $\begin{array}{c}\text { معدل التغيري السنوي } \\
(\widehat{b} / \bar{x})^{*} \mathbf{1 0 0}\end{array}$ & المتوسط & $\mathbf{F}$ & $\mathbf{R}^{-2}$ & $\mathbf{R}^{2}$ & معادلات الاتجاه الزمنى العام & المتغير التابع \\
\hline 10.2 & 1787.24 & 163.53 & 0.94 & 0.95 & $\begin{array}{c}\text { صه = } 182.36+6930.8 \text { سهـ } \\
\quad(12.79)\end{array}$ & قيمة الحبوب الزيتية \\
\hline 17.41 & 724.04 & 40.53 & 0.80 & 0.82 & 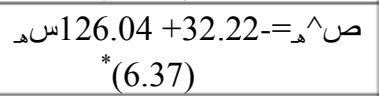 & قالزيتة الفاقد من الحبوب \\
\hline 7.73 & 131.9 & 32.92 & 0.76 & 0.79 & صه = & كمية الفاقد من الحبوب \\
\hline
\end{tabular}

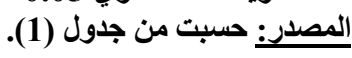

الذرة الثشامية الصيفي ، 5070 جنيه لفدان القطن مما

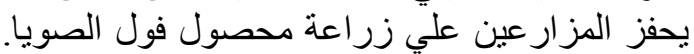

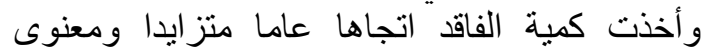

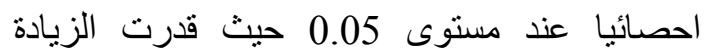
السنوية بمقدار 5.19 الف طن تمثل

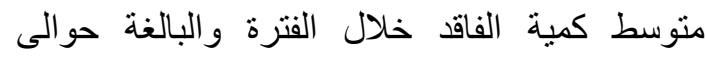
42.23 الف طن. 2.4.محصول الفول السودانى الصيفى:

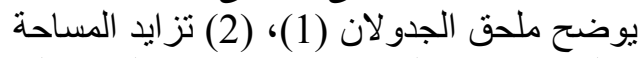

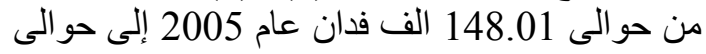
152.9 الف فدان عام 2016 بنسبة زيادة تقدر بنحو الف الفي \%3.30.، و من أهم أصناف التقاوي ذات الإنتاجية

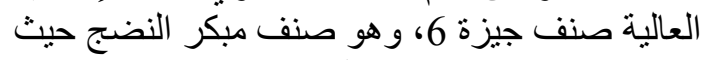

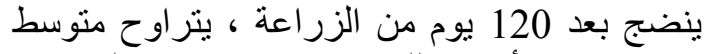

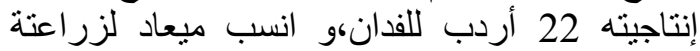
منتصف شهر أبريل (نشرة الإرشاد الزراعي رقم لزران .2016- 1364
1.4. محصول فول الصويا:

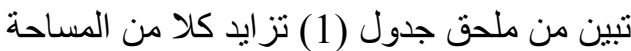
والإنتاجية والإنتاج من من 20.1 الف فن فدان، 1.29

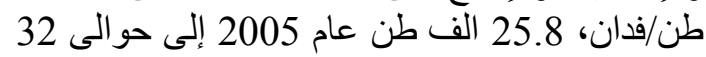
الف فدان، 1.4 طن/فدان، 45.8 الف طن طن خلال عام

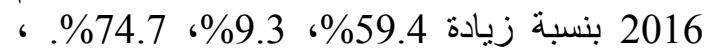
وذللك نتيجة جهود الدولة في تنمية تللك المحاصيل وفي ضوء تنفيذ الإستر اتيجيات المختلفة و المتمنلة في

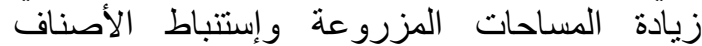
الجديدة من التقاوي ذات الإنتاجية العالية مثل أصناف الإناف

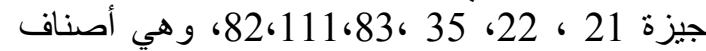

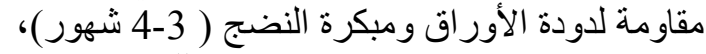
يتراوح متوسط انتاجيتها 1.5 طن للفدان الإن (نشرة

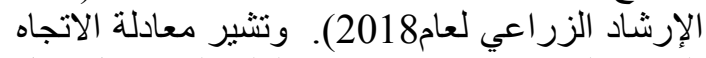

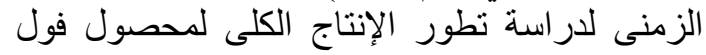
الصويا بملحق جدول(2) إلى تزايد الإنتاج سنويا

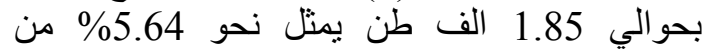
متوسط الفترة للإنتاج الكلى والبالغ نحو 32.8 الف 
ملحق جدول (1): تطور بعض المتغيرات الاقتصادية لمحاصيل الحبوب الزيتية الغذائية فى مصر خلال الفترة (2005-2016).

\begin{tabular}{|c|c|c|c|c|c|c|c|c|c|c|c|c|c|c|c|c|c|c|}
\hline \multicolumn{9}{|c|}{ 2- الفول السودانى الصيفى } & \multicolumn{9}{|c|}{ المحاصيل الزيتية: 1- فول الصويا الصيفى } & \multirow[b]{2}{*}{ 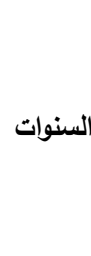 } \\
\hline طالالف & بالالف طن الإسلاك & العائد & إلتكاليف & جنيه & أردب/ الأسعار & بالالف الإنتاج & طن/فـان الإنتاجية & فالاف & بالالف & الإستهلاك & القائد & إلتكاليف & جنا جلإيراد & جنيه/طن الإسعار & طالإلفتاج & طن/فـان & فالاف & \\
\hline 2 & 168 & 1607 & 1780 & 3387 & 184 & 199.35 & 1.35 & 148.01 & 19 & 617 & 798 & 1610 & 2408 & 1858 & 25.82 & 1.29 & 20.08 & 2005 \\
\hline 2 & 187 & 2423 & 1865 & 4288 & 213 & 183.91 & 1.39 & 132.08 & 18 & 600 & 698 & 1777 & 2475 & 1908 & 23.02 & 1.29 & 17.79 & 2006 \\
\hline 2 & 172 & 3957 & 2233 & 6190 & 334 & 217.53 & 1.40 & 155.31 & 35 & 1160 & 911 & 1790 & 2701 & 1953 & 25.61 & 1.38 & 18.54 & 2007 \\
\hline 2 & 203 & 3544 & 3165 & 6709 & 348 & 208.82 & 1.43 & 146.17 & 16 & 539 & 989 & 2613 & 3602 & 2161 & 29.17 & 1.41 & 20.67 & 2008 \\
\hline 2 & 197 & 4831 & 3229 & 8060 & 464 & 198.01 & 1.30 & 151.85 & 20 & 683 & 1372 & 2643 & 4016 & 2207 & 26.39 & 1.55 & 17.06 & 2009 \\
\hline 18 & 188 & 5191 & 3489 & 8680 & 503 & 201.95 & 1.27 & 158.95 & 19 & 641 & 681 & 2773 & 3454 & 2316 & 43.29 & 1.19 & 36.23 & 2010 \\
\hline 2 & 169 & 6003 & 3786 & 9789 & 528 & 206.51 & 1.33 & 154.81 & 70 & 811 & 1447 & 3143 & 4590 & 2866 & 29.77 & 1.31 & 22.72 & 2011 \\
\hline 2 & 188 & 6404 & 4020 & 10424 & 557 & 205.39 & 1.38 & 148.70 & 48 & 554 & 3878 & 3188 & 7066 & 4117 & 25.94 & 1.52 & 11.11 & 2012 \\
\hline 2 & 167 & 7489 & 4058 & 11547 & 594 & 204.79 & 1.39 & 147.88 & 85 & 983 & 3570 & 3414 & 6984 & 4210 & 32.75 & 1.46 & 22.42 & 2013 \\
\hline 14 & 175 & 8366 & 4333 & 12699 & 660 & 183.28 & 1.36 & 134.44 & 56 & 925 & 3273 & 3530 & 6803 & 4261 & 39.86 & 1.39 & 28.49 & 2014 \\
\hline 12 & 158 & 8404 & 4638 & 13042 & 681 & 197.25 & 1.38 & 143.06 & 50 & 669 & 2934 & 3824 & 6758 & 4342 & 46.84 & 1.38 & 33.97 & 2015 \\
\hline 10.79 & 170 & 7160 & 6709 & 13869 & 707 & 205.9 & 1.35 & 152.9 & 70.8 & 808.6 & 1574 & 5228 & 6802 & 4388 & 45.1 & 1.41 & 32.0 & 2016 \\
\hline 5.90 & 178.5 & 5448.3 & 3608.8 & 9057 & 481.08 & 201.06 & 1.36 & 147.84 & 42.23 & 749.2 & 1843.75 & 2961.08 & 4804.8 & 3048.92 & 32.79 & 1.38 & 23.92 & المتوسط \\
\hline
\end{tabular}

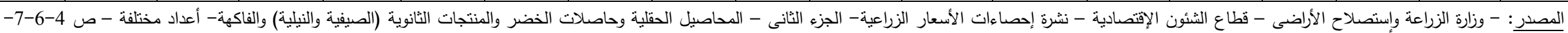
54

- وزارة الزراعة وإستصلاح الأراضى - قطاع الثئون الإقتصادية- نشرة الإحصاءات الزراعية- الجزء الثانى- المحاصيل الصيفية والنيلية - أعداد مختلفة - ص 389-390.

- نشرة الاخل الزراعى القومى - أعداد مختلفة - ص صاعل 12.

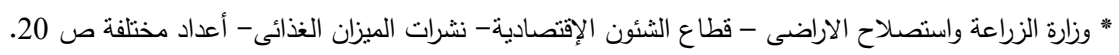


ملدق جدول (2): تطور معدلات الاتجاه الزمنى العام لبعض المتغيرات الاقتصادية للمحاصيل الزيتية خلال الفترة (2005-2016).

\begin{tabular}{|c|c|c|c|c|c|c|}
\hline$(\widehat{b} / \bar{x})^{* 100}$ & المتوسط & $\mathbf{F}$ & $\bar{R}^{2}$ & $\mathbf{R}^{2}$ & معادلات الاتجاه الزمنى العام & المحاصيل الزيتية \\
\hline & & & & & & (1) فول الصويا الصيفى \\
\hline 5.64 & 3048.92 & 15.06 & 0.56 & 0.60 & 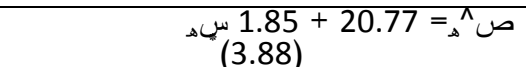 & 1- الانتاج بالالف طن \\
\hline 10.39 & 2961.08 & 64.21 & 0.85 & 0.87 & 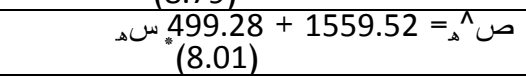 & جملة الايراد جنيه/فدان \\
\hline 9.02 & 2961.08 & 0.89 & 0.89 & 0.90 & صمث = 1224.47 + 267.17 سئه & اجمالى التكاليف جنب//فدان \\
\hline
\end{tabular}

\begin{tabular}{|c|c|c|c|c|c|c|}
\hline$(\widehat{b} / \bar{x})^{* 100}$ & المتوسط & $\mathrm{F}$ & $\bar{R}^{2}$ & $\mathrm{R}^{2}$ & معادلات الاتجاه الزمنى العام & (2) الفول السودانى \\
\hline 10.02 & 481.08 & 277.75 & 0.96 & 0.97 & 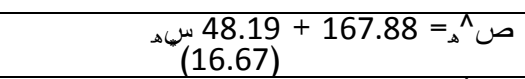 & الاسعار جنيه/أردب \\
\hline 10.50 & 9057 & 1008.49 & 0.99 & 0.99 & صدم = 2874.23 + & جملة الايراد جنيه/فدان \\
\hline 9.79 & 3608.8 & 74.54 & 0.78 & 0.88 & 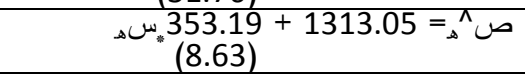 & اجمالى التكاليف جنيد/فدان \\
\hline 10.98 & 5448.3 & 110.43 & 0.91 & 0.92 & ص^ه = 1561.18 + 598.01 سيه & صافى العائد جنيه/ فدان \\
\hline
\end{tabular}




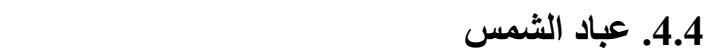
يتضح من ملحقان الجدولين (3، 4) تناقص خلص

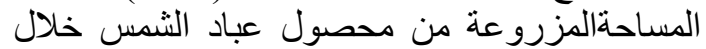
فترة الدراسة من 31.5 الف فدان عام 2016 الف 2005 إلى نحو 15.2 الف فدان عام 20016 بنسبة تناقص 51.7 5 عام 2005، ومن أصناف المحصول سخا 53 ، ، و و

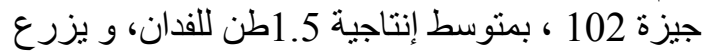

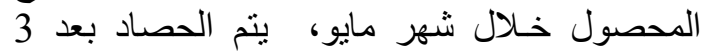

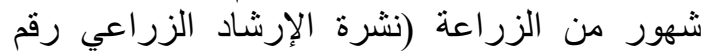

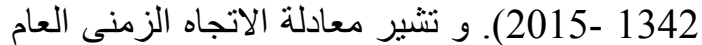

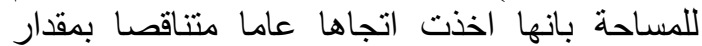

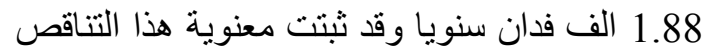
احصائيا عند مستوي معنويه 0.05، بمقدار 1.88 الف فدان سنويا تمثل \% 7.89\% من منوسط الفترة

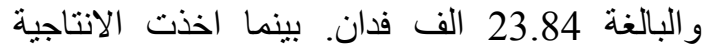

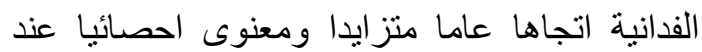
مستوى 0.05 وقدرت الزيادة السنوية بمقدار 0.04 طن للفدان تمثل 3.57\% من منتوسط الفترة و البالغة الزية 1.12 طن للفدان، وتذبذب الانتاج الكلى بين الارتفاع الئاع

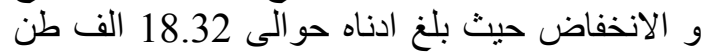

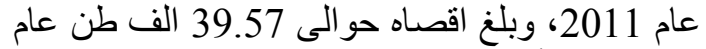

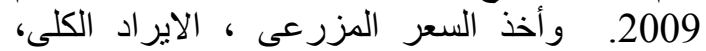
صافى العائد الفدانى اتجاها متز ايدا بمقدار 243.75 جنيه/ طن، 344.1جنيه ، ومعنوى احصائيا عند مستوى 0.05 وتمثل نسبة

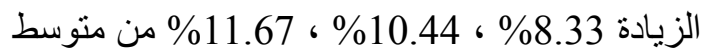

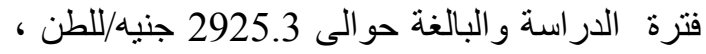

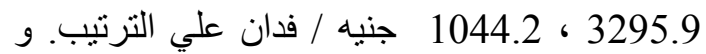

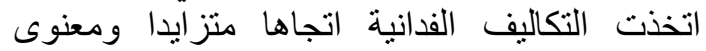
احصائيا عند مستوى 0.05 حيث قدرت النياتئ الزيادة السنوية للتكاليف الفدانية حوالى 222.2 جنيه تمثنل 9.87 من منوسط الفترة و البالغة حو الى تلى 222.81 .8 جنيه للفدان. ، و هي تكلفة الفيلة أقل من تكلفة الفرصة البديلة لتكاليف المحاصيل الصيفية المنافسة، و التي لني بلغت 7707 جنيه لفدان الطماطم، 13939 النيهيه لفدان

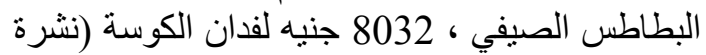

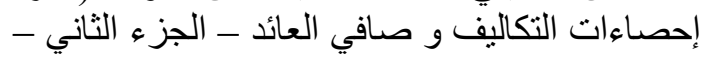
المحاصيل الحقلية و الخضر الصيفية و النيانية النيلية و والني

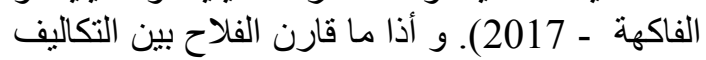

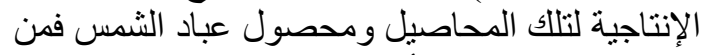
منطلق الذي يفترض أن المنتج رشيد فإن ذلإلك يحفز

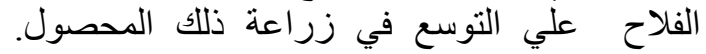

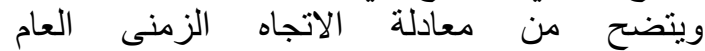

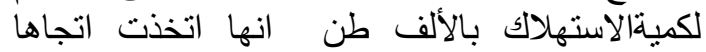

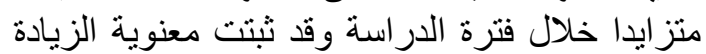
احصائيا عند مستوى فترة معنوية 0.05 بمقدار 6.04

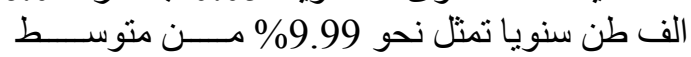

تبين من ملحق الجدولان السابق الاشارة اليهما

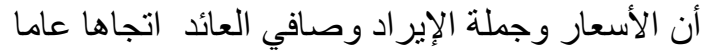

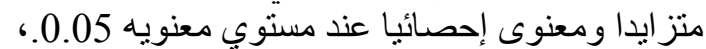
وقدرت الزيادة السنوية بحو الى 48.19 جنيانيا عنيه/ للأردب

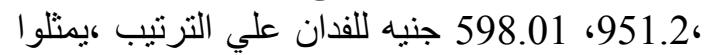

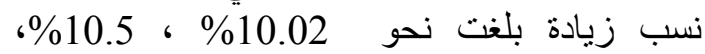

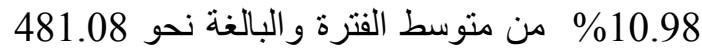
جنيه/ للأردب ، 9057 ، 5448.3 جنية الإنيه للفدان علي الترتيب. إجمالى التكاليف الإنتاجية للفدان اخذت لإن

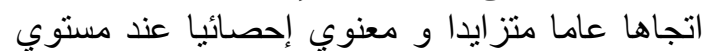
معنويه 0.05، بمقدار 353.19 جنيه للفدان سنويا بنسبة زيادة قدرت بنحو 99.79\% من منتوسط الفترة

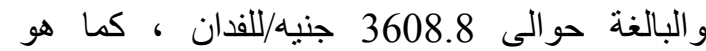
موضح بملحق جدول (2) ، و و هي تكلفة أقل من تكلفة

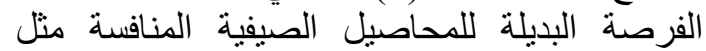

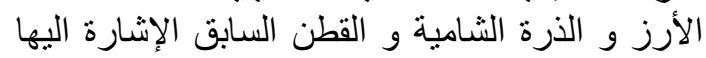

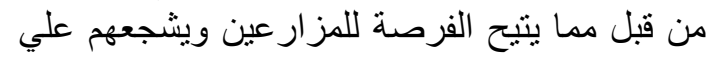
التوسع في زر اعنة .

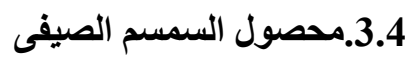

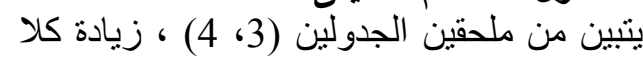
من الاسعار جملة الإيراد ، وصنافي الجداين العائد الفداني كني و اتخاذهم اتجاها متز ايدا معنوى الحصائيا الزيا عند مستوي

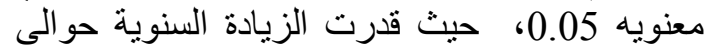

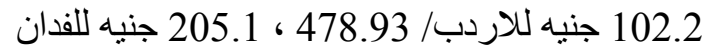

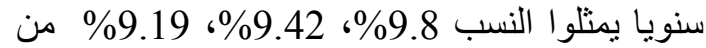
متوسط فترة الدراسة و البالغة حو الى 1042.4 جنيه

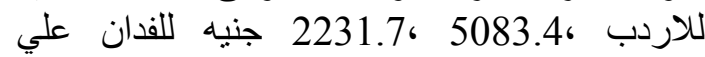
الترتيب. ، و واتخذت اجمالى التكاليف الانتاجية اتجاها

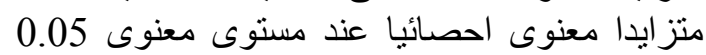

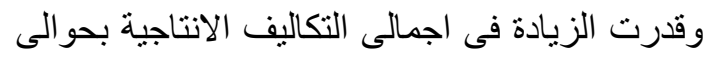

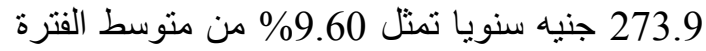

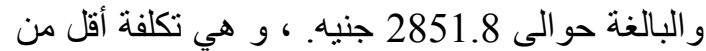
تكلفة الفرصة البديلة للمحاصيل الصيفية المنافسة، والتي بلغت 3608.8 جنيه لفدان الفول السوداني الصيفي ، 2961.08 جنيه لفدان فول الصويا الصيفي لفي الفي الفي

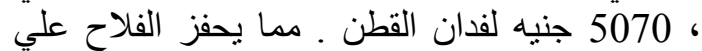

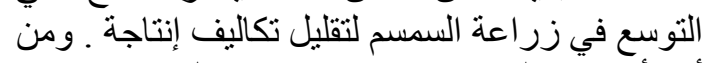
أهم أصناف السمسم جيزة 32 ، شندويل 3 ، نوشكي

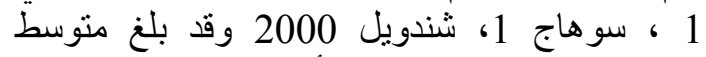

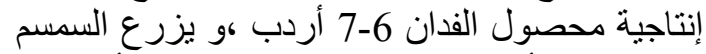

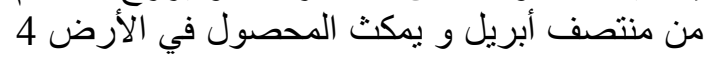
شهور حتى النضج (نشرة الإرشاد الزراعي لعام الأرضي

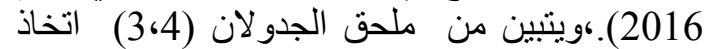

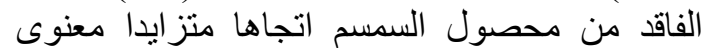
احصائيا عند مستوى معنوية 0.05 وقدرت الفئ الزيادة فى الفاقد بحو الى 0.56 الف طن سن سنويا تمثل نسبة 26.67\% من منوسط الفترة و البالغة حو الى سلى 2.2 الف نف 
ملحق جدول (3): نطور بعض المتغيرات الاقتصادية لمحاصيل الحبوب الزيتية الغذائية فى مصر خلال الفترة (2005-2016).

\begin{tabular}{|c|c|c|c|c|c|c|c|c|c|c|c|c|c|c|c|c|c|c|}
\hline \multicolumn{9}{|c|}{ 4- عباد الثمس } & \multicolumn{9}{|c|}{ 3- السمسم الصيفى } & \multirow[b]{2}{*}{ السنوات } \\
\hline طالالف & 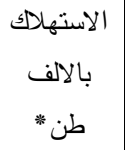 & صافى العائد & $\begin{array}{l}\text { التكاليف } \\
\text { جنيه }\end{array}$ & جنيه & جنيه/طن اردب & $\begin{array}{l}\text { بالالف } \\
\text { طن } \\
\text { بالناج }\end{array}$ & طن/فدان & فالاف & بالالف & بالالف & $\begin{array}{c}\text { العائدى } \\
\text { الفان جنيه }\end{array}$ & التكاليف & جنيه & جنيه/طن الاسبعار & بالالف & طن/فانان & فالاف & \\
\hline 2 & 42 & 636 & 1144 & 1780 & 1839 & 30.41 & 0.97 & 31.46 & - & 44 & 1007 & 1483 & 2490 & 491 & 36.72 & 0.55 & 66.86 & 2005 \\
\hline 1 & 28 & 646 & 1199 & 1845 & 1895 & 35.77 & 1 & 35.65 & - & 46 & 1101 & 1535 & 2636 & 516 & 40.61 & 0.55 & 73.36 & 2006 \\
\hline 1 & 34 & 696 & 1225 & 1921 & 1927 & 27.63 & 1.02 & 27.18 & - & 47 & 1839 & 1861 & 3700 & 708 & 41.52 & 0.56 & 74.87 & 2007 \\
\hline 1 & 31 & 259 & 2036 & 2295 & 2118 & 20.39 & 1.06 & 19.23 & 1 & 55 & 1654 & 2439 & 4093 & 809 & 36.46 & 0.55 & 66.35 & 2008 \\
\hline 1 & 24 & 794 & 2023 & 2817 & 2711 & 39.57 & 0.99 & 39.65 & - & 45 & 1569 & 2508 & 4077 & 908 & 49.99 & 0.51 & 98.79 & 2009 \\
\hline 3 & 93 & 787 & 2214 & 3001 & 2750 & 36.82 & 1.04 & 35.26 & - & 62 & 1787 & 2593 & 4380 & 936 & 46.16 & 0.53 & 87.87 & 2010 \\
\hline 5 & 91 & 718 & 2279 & 2997 & 2847 & 18.32 & 1.05 & 17.54 & 4 & 61 & 1804 & 2964 & 4768 & 972 & 43.20 & 0.55 & 78.33 & 2011 \\
\hline 6 & 96 & 1240 & 2506 & 3746 & 3415 & 19.99 & 1.13 & 17.71 & 4 & 62 & 3457 & 3237 & 6694 & 1357 & 31.27 & 0.54 & 57.58 & 2012 \\
\hline 5 & 80 & 1785 & 2632 & 4417 & 3468 & 19.04 & 1.26 & 15.16 & 3 & 45 & 3594 & 3276 & 6870 & 1393 & 32.76 & 0.55 & 59.61 & 2013 \\
\hline 4 & 64 & 1574 & 2711 & 4285 & 3605 & 21.53 & 1.32 & 16.32 & 2 & 33 & 3704 & 3420 & 7124 & 1429 & 37.47 & 0.59 & 63.82 & 2014 \\
\hline 12 & 79 & 2357 & 2775 & 5132 & 3764 & 22.17 & 1.41 & 15.68 & 7 & 44 & 3352 & 3579 & 6931 & 1478 & 49.82 & 0.57 & 87.13 & 2015 \\
\hline 8.53 & 93.71 & 1038 & 4277 & 5315 & 4765 & 18.9 & 1.24 & 15.2 & 5.4 & 48 & 1912 & 5326 & 7238 & 1512 & 39.6 & 0.57 & 69.8 & 2016 \\
\hline 4.13 & 60.48 & 1044.2 & 2251.8 & 3295.9 & 2925.3 & 25.88 & 1.12 & 23.84 & 2.2 & 49.3 & 2231.7 & 2851.8 & 5083.4 & 1042.4 & 40.47 & 0.55 & 73.7 & المتوسط \\
\hline
\end{tabular}

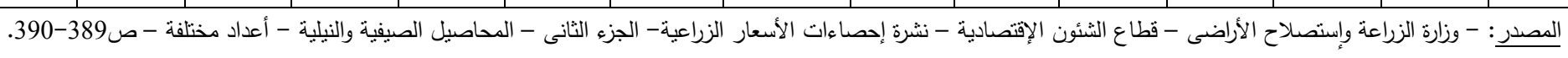

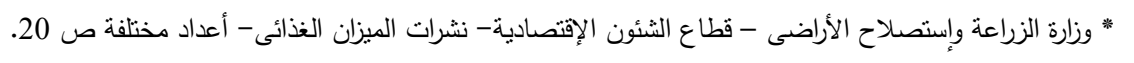




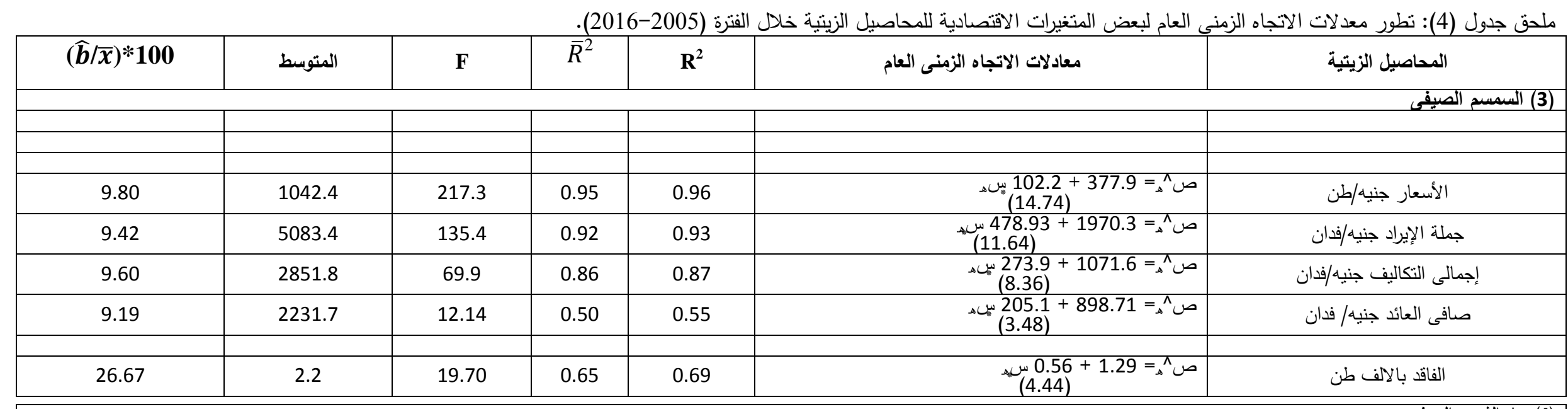

\begin{tabular}{|c|c|c|c|c|c|c|}
\hline & & & & & & (4) عباد الثمس الصيفي \\
\hline$(\widehat{b} / \bar{x})^{* 100}$ & المتوسط & $\mathbf{F}$ & $\bar{R}^{2}$ & $\mathbf{R}^{2}$ & معادلة الاتجاة العام & المتغير التابع \\
\hline $7.89-$ & 23.84 & 11.17 & 0.48 & 0.53 & 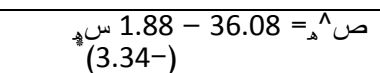 & المساحة بالالف فدان \\
\hline 3.57 & 1.12 & 32.9 & 0.74 & 0.77 & صد^= $0.89+0.04$ سيه 0.04 (5.74) & الإنتاجية طن/فدان \\
\hline 8.33 & 2925.3 & 151.5 & 0.93 & 0.94 & ص^^= = 1340.97 + (12.31) & الأسعار جنيه/طن \\
\hline 10.44 & 3295.9 & 258.1 & 0.96 & 0.96 & 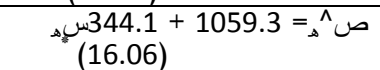 & جملة الإيراد جنيد/فدان \\
\hline 9.87 & 2251.8 & 57.5 & 0.84 & 0.85 & صـ & إجمالى التكاليف جنيه/فدان \\
\hline 11.67 & 1044.2 & 12.05 & 0.50 & 0.55 & ص^ه = 251.76 + & صافى العائد جنيه/ فدان \\
\hline 9.99 & 60.48 & 11.55 & 0.51 & 0.56 & 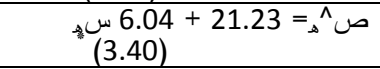 & كمية|الإستهلالك بالاف طن \\
\hline 19.37 & 4.13 & 15.93 & 0.060 & 0.64 & ص^ه = 1.07 + 1.07 سنه. & كمية/الفاقد بالالف طن \\
\hline
\end{tabular}


المزروعة بمحصول الكتان اتخذت اتجاها عاما متناقصا بلغ حوالى 1.43 الف فدان سنويا ومعنوى

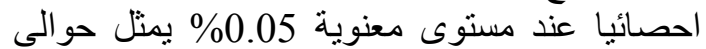
12.12\% من منوسط الفترة موضع الدراسة و البالغة

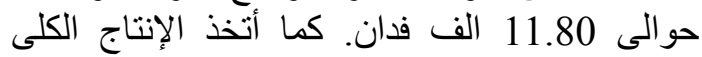

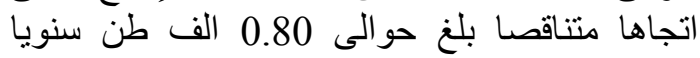

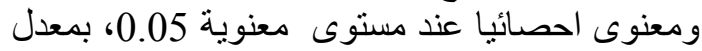
تناقص قدر بنحو 11.51\% من منوسط فترة الدر اسة و البالغة 6.95 الف طن، ومن ون أهم الأصناف سخا

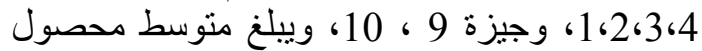
البذور 700 كجم للفدان حسب الصنف و و وأنسب ميعاد

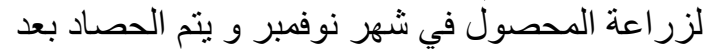

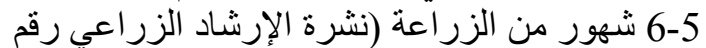

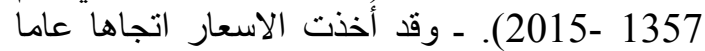

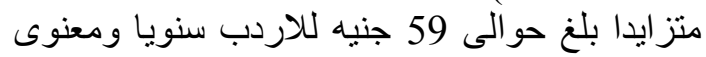

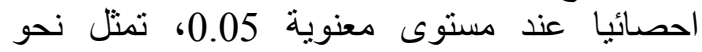
10.68\% من منوسط فترة الدراسة و البالغة حوالى لئل

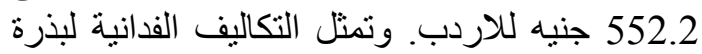

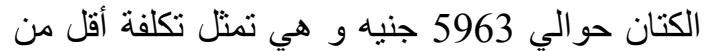

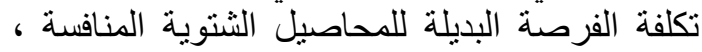

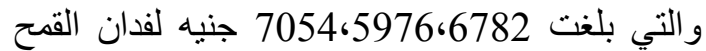

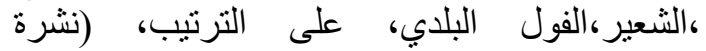
الإحصاءات الزراعية ـالجزء الثانى - الثية المحاصيل

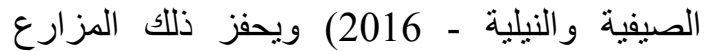

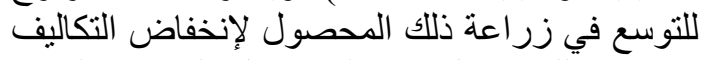
الإنتاجية للمحصول عن المحاصيل المنافسة السابق لإن اليقال الإشارة اليها.

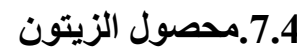

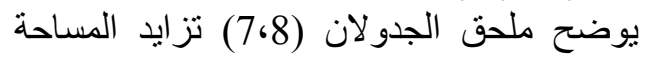

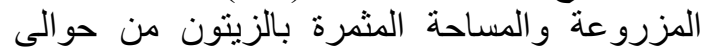

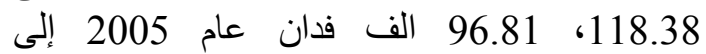
251.07، 161.61 الف فدان عام 2016 بنسبة زيادة تقدر بنحو 112.09\%، 66.94\%، ومن أهم أهم الأصناف التفاحي ، العجيزي الثامي، الكلاماتا، ودولسي، وييلغ متّوسط إنتاج الفذان 3.86 طن (نشرة

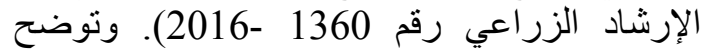

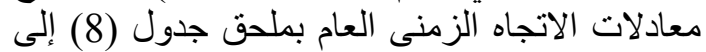

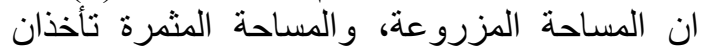

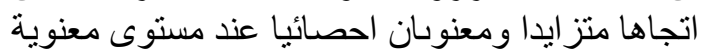
0.05 وقدرت الزيادة السنوية بحو الى الى 12.83، 6.09

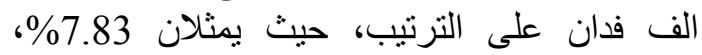

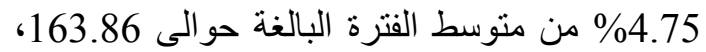
128.09 الف فدان ، كما تأخذ قيمة الانتاج اتجاهيا

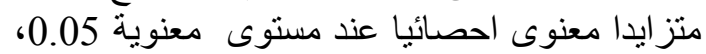
وقدرت الزيادة السنوية بحوالى 86.11 مليون جنيه تمثل نسبة 7.73\% عن متوسط الفترة والئية والمقدر بحوالى 1.11 مليار جنيه ، و و تمثل إجمالي التكاليف

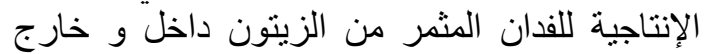
الو ادي حو الي 19325، 18703 جنيه علي الترتيب.
الفترة والبالغة نحو 60.48 الف طن. بينما إتخذت كمية الفاقد من محصول عباد الثمس بالألف بالف طن فقد

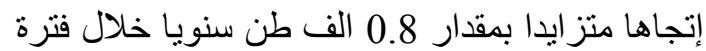

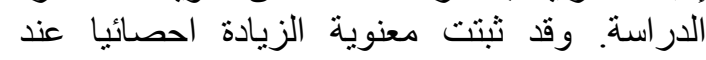

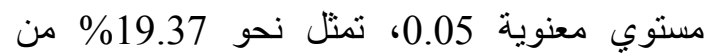
متوسطُ الفترة و البالغة نحو 4.13 الف طن.

- 5.4. - 5ذبرة القطن

توضح معادلات الاتجاه الزمنى العام بملحق

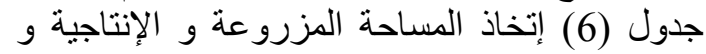

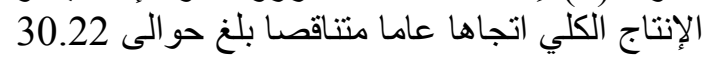

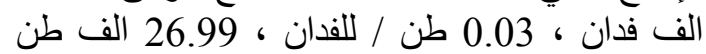
سنويا ، على الترتيب معنوى احصائيا عند مستوى النو

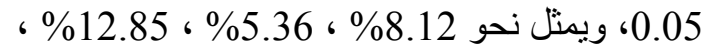
على الترتيب من متوسط الفترة موضع الدراسة

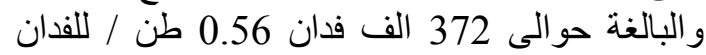

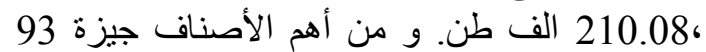
،

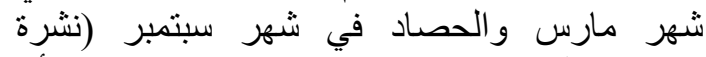

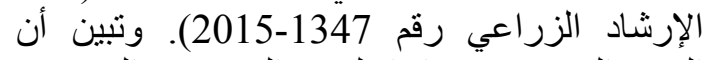

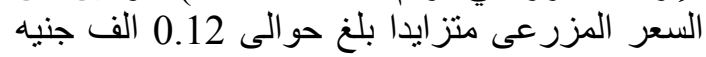

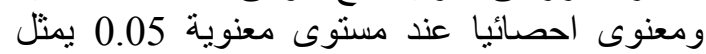
نحو 10.34\% من منوسط فترة الدراسة والبالغة حوالى 1.16 الف جنيه. وتنين أن التكاليف الكلية

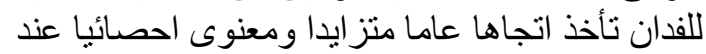

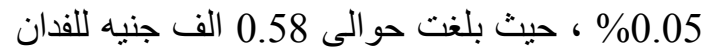
سنويا تمثل نحو 11.44\% من متوسط فترة الدراسة و البالغة حوالى 5.07 الف جنيه وهي أقلى من فن تكلفة الفية

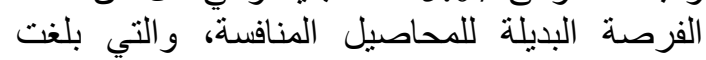

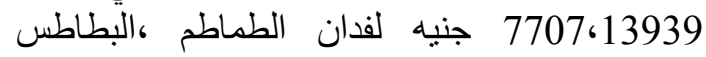

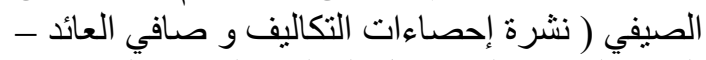

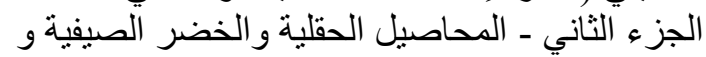

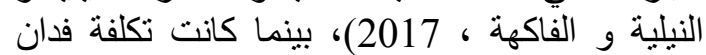
بذرة القطن أعلي من تكلفة الفرصة البديلة لفدان

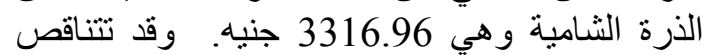
المساحة المزروعة بمحصول القطن لانه يشغله

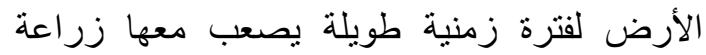

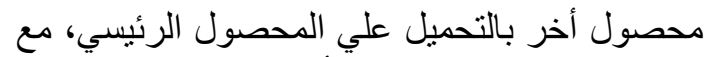
صعوبة تسويق المحصول. أما إستهلاك زيول الريوت بذي، بذرة

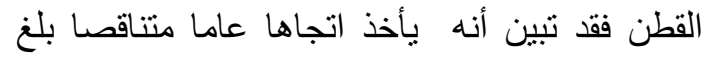
حو الى 25.25 الف طن سنويا معنوى احصائيا عند بند

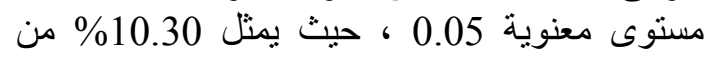
منوسط فترة الدراسة و البالغة حوالى الى 245.2 الف بن

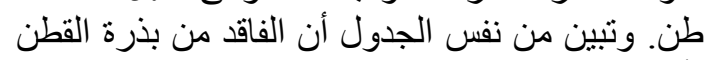

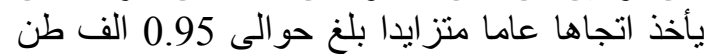

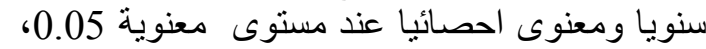

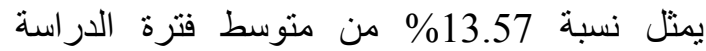

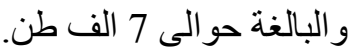

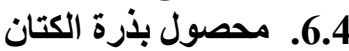

يتبين من ملحقان الجدولين (6، 5) أن المساحة 
ملحق جدول (5): تطور بعض المتغرات الاقتصادية لبعض المحاصيل الني يستخرج من عصر بذورها الزيوت فى مصر خلال الفترة (2005-2016).

\begin{tabular}{|c|c|c|c|c|c|c|c|c|c|c|c|c|c|c|}
\hline \multicolumn{5}{|c|}{ 6- بذرة الكتان } & \multicolumn{9}{|c|}{ 5- محصول بذرة القطن } & \multirow[b]{2}{*}{ السنوات } \\
\hline بالالف جنيه الإنتاج & جنيه/ اردب الاسعار & بالالف طن الانتاج & طن الانتاجية & بالاف فدان & بالالف & بالالف & بالعائد للفدان & $\begin{array}{c}\text { الايراد الكلى للفدان } \\
\text { بالالف جنيه }\end{array}$ & بالالف التباليف للفدان & 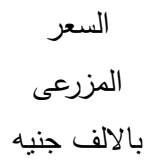 & بالالف الانتاج & طن/فدان & بالاف فدان & \\
\hline 548 & 251 & 11.33 & 0.69 & 16.35 & 4 & 394 & 3.03 & 4.68 & 1.65 & 0.73 & 394 & 0.60 & 657 & 2005 \\
\hline 21647 & 271 & 6.90 & 0.44 & 15.61 & 4 & 394 & 2.68 & 5.65 & 2.97 & 0.78 & 394 & 0.74 & 536 & 2006 \\
\hline 28656 & 286 & 12.20 & 0.58 & 21 & 3 & 336 & 1.29 & 4.74 & 3.44 & 0.671 & 336 & 0.79 & 424 & 2007 \\
\hline 39134 & 402 & 11.88 & 0.59 & 20.10 & 3 & 321 & 1.23 & 5.35 & 4.12 & 0.806 & 193 & 0.62 & 312 & 2008 \\
\hline 32352 & 500 & 7.89 & 0.62 & 12.78 & 2 & 193 & 0.42 & 4.41 & 3.99 & 0.679 & 145 & 0.51 & 284 & 2009 \\
\hline 19457 & 521 & 4.55 & 0.57 & 7.95 & 6 & 145 & 4.28 & 8.85 & 4.57 & 1.34 & 187 & 0.51 & 369 & 2010 \\
\hline 22883 & 615 & 4.54 & 0.56 & 8.07 & 11 & 187 & 3.22 & 8.41 & 5.19 & 1.07 & 218 & 0.42 & 520 & 2011 \\
\hline 31587 & 673 & 5.72 & 0.56 & 10.18 & 13 & 218 & 1.22 & 6.71 & 5.49 & 1.17 & 211 & 0.63 & 333 & 2012 \\
\hline 11451 & 720 & 1.94 & 0.57 & 3.41 & 13 & 211 & 2.83 & 8.46 & 5.63 & 1.47 & 134 & 0.47 & 287 & 2013 \\
\hline 27276 & 740 & 4.48 & 0.65 & 6.89 & 8 & 134 & 0.45 & 7.91 & 7.46 & 1.25 & 164 & 0.44 & 369 & 2014 \\
\hline 31428 & 772 & 4.97 & 0.67 & 7.42 & 10 & 164 & $0.19-$ & 5.44 & 5.63 & 1.25 & 83 & 0.34 & 241 & 2015 \\
\hline 29714.71 & 875.91 & 2.14 & 0.62 & 3.19 & 12.67 & 93.65 & 8.33 & 19.07 & 10.74 & 2.71 & 62 & 0.47 & 132 & 2016 \\
\hline 24677.81 & 552.24 & 6.55 & 0.59 & 11.08 & 7.47 & 232.55 & 2.39 & 7.47 & 5.07 & 1.16 & 210.08 & 0.56 & 372 & المتوسط \\
\hline
\end{tabular}

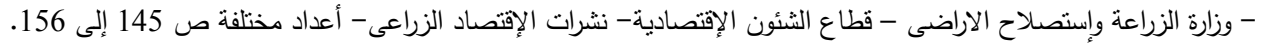


ملحق جدول (6): تطور معدلات الاتجاه الزمنى العام لبعض المتغيرات الاقتصادية للمحاصيل التي يستخرج من عصر بذورها الزيوت خلال الفترة (2005-2016).

\begin{tabular}{|c|c|c|c|c|c|c|}
\hline$(\widehat{b} / \bar{x})^{* 100}$ & المتوسط & $\mathrm{F}$ & $\bar{R}^{2}$ & $\mathrm{R}^{2}$ & معادلات الاتجاه الزمنى العام & المحاصيل الزيتية \\
\hline & & & & & & (5) بذرة القطن \\
\hline $8.12-$ & 372 & 13.46 & 0.53 & 0.57 & صد^= & المساحة بالالف فدان \\
\hline $5.36^{-}$ & 0.56 & 12.95 & 0.52 & 0.56 & 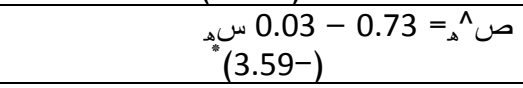 & الإنتاجية طن/فدان \\
\hline $12.85^{-}$ & 210.08 & 34.28 & 0.75 & 0.77 & صـ^= 385.56 - 38.99 سـه (5.86-) & الإنتاج بالالف طن \\
\hline 10.34 & 1.16 & 15.05 & 0.56 & 0.60 & صد^ه = $0.12+0.37$ سيه & السعر المزرعى بالالف جنيه \\
\hline 11.44 & 5.07 & 6.21 & 0.77 & 0.79 & 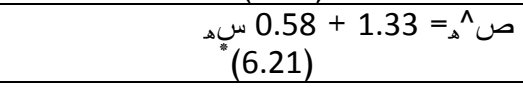 & التكاليف الكلية للفدان بالالف جنيه \\
\hline $10.30^{-}$ & 245.2 & 25.1 & 0.71 & 0.74 & صد^= 2596.65 صـ 39.25 سهـ & الإستهلاك بالألف طن \\
\hline 13.57 & 7 & 12.23 & 0.58 & 0.76 & صـ = $0.95+1.27$ س 0.95 سه & الفاقد بالألف طن \\
\hline
\end{tabular}

\begin{tabular}{|c|c|c|c|c|c|c|}
\hline$(\widehat{b} / \bar{x})^{* 100}$ & المتوسط & $\mathrm{F}$ & $\bar{R}^{2}$ & $\mathrm{R}^{2}$ & معادلات الاتجاه الزمنى العام & (6) بذرة الكتان \\
\hline $12.12-$ & 11.80 & 18.12 & 0.63 & 0.67 & صدئ = 20.35 - 1.43 سليه & المساحة بالألف فدان \\
\hline $11.51-$ & 6.95 & 12.69 & 0.54 & 0.59 & ص ^ه = 11.74 - 11.80 سن & الإنتاج بالألف طن \\
\hline 10.68 & 552.2 & 334.2 & 0.97 & 0.97 & صـ = 167.91 + 169 سيه & الأسعار جنيه/إردب \\
\hline
\end{tabular}

المصدر: ملحق جدول (5). 
ملحق جدول (7): تطور بعض المتغيرات الاقتصادية لبعض الدحاصيل التي يستخرج من عصر لحومها و بذورها الزيوت الغذائية فى مصر خلال الفترة (2005-2016).

\begin{tabular}{|c|c|c|c|c|c|c|c|c|c|c|c|c|c|c|c|}
\hline \multicolumn{7}{|c|}{ 8- الذرة الثامية الصيفية والنيلية البيضاء والصفراء } & \multicolumn{8}{|c|}{ 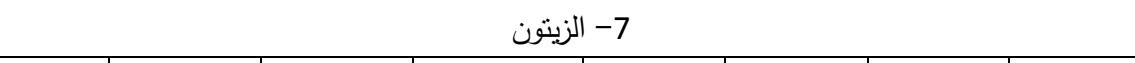 } & \multirow[b]{2}{*}{ السنوات } \\
\hline متوسط صافى العائد & منتية الايراد & منتوسط التكاليف & 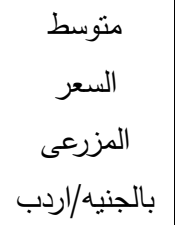 & الانتاج & طن/فدان & بالاف فدان المساحة & بالالف & بالالف & جنيه/طن & قبمة الإنتاج & بالالف & طن/فدان الانتاجية & المبالاف & الكساحة & \\
\hline 1498 & 3409.5 & 1911.5 & 145 & 7698.04 & 3.41 & 2257.37 & 61 & 303 & 2114.9 & 665.06 & 314.45 & 3.25 & 96.81 & 118.38 & 2005 \\
\hline 1604 & 3617 & 2013 & 151 & 6908.61 & 3.17 & 2176.86 & 81 & 539 & 2167.01 & 1180.24 & 544.64 & 5.03 & 108.29 & 125.37 & 2006 \\
\hline 2779 & 5148 & 2369 & 221 & 6929.53 & 3.35 & 2068.86 & 74 & 496 & 1538.17 & 779.93 & 507.05 & 4.58 & 110.76 & 135.69 & 2007 \\
\hline 1499.5 & 4597.5 & 3098 & 197.5 & 7401.41 & 3.32 & 2229.18 & 68 & 453 & 1548.86 & 743.56 & 480.07 & 4.37 & 109.95 & 150.32 & 2008 \\
\hline 1408 & 4505.5 & 3097.5 & 192 & 7686.09 & 3.28 & 2340.67 & 59 & 396 & 1583.13 & 710.84 & 449.01 & 4.08 & 110.18 & 158.06 & 2009 \\
\hline 222.5 & 566.5 & 3444 & 263.5 & 7183.01 & 3.07 & 2343.13 & 77 & 354 & 1985.65 & 776.25 & 390.93 & 3.27 & 119.43 & 163.27 & 2010 \\
\hline 2404 & 6128.5 & 3724.5 & 270 & 6876.47 & 3.25 & 2115.07 & 66 & 442 & 2384.10 & 1095.85 & 459.65 & 3.67 & 125.39 & 155.82 & 2011 \\
\hline 2735.5 & 668 & 3932.5 & 295.5 & 8093.64 & 3.26 & 2479.39 & 79 & 529 & 2438.70 & 1373.16 & 563.07 & 4.11 & 137.03 & 202.74 & 2012 \\
\hline 2499.5 & 6731 & 1242 & 302.5 & 7956.59 & 3.24 & 2453.19 & 74 & 492 & 2453.19 & 1329.113 & 541.79 & 3.96 & 146.93 & 240.46 & 2013 \\
\hline 2504 & 6926.5 & 4422.50 & 307 & 8059.91 & 3.26 & 2474.38 & 78 & 523 & 2453 & 1387.59 & 565.67 & 3.91 & 144.85 & 237.45 & 2014 \\
\hline 2178.5 & 6820 & 4641.5 & 312 & 780.318 & 3.09 & 2525.17 & 97 & 645 & 2482.77 & 1735.28 & 698.93 & 4.21 & 165.90 & 227.68 & 2015 \\
\hline 1499 & 7406.5 & 5907.5 & 335 & 7817.64 & 3.20 & 2445.88 & 84.73 & 570.05 & 2557.78 & 1587.28 & 626.10 & 3.87 & 161.61 & 251.07 & 2016 \\
\hline 2069.29 & 5635.38 & 3316.96 & 249.33 & 7534.51 & 3.24 & 2325.76 & 74.9 & 478.5 & 2142.27 & 1113.68 & 511.78 & 4 & 128.09 & 163.86 & المنوسط \\
\hline
\end{tabular}

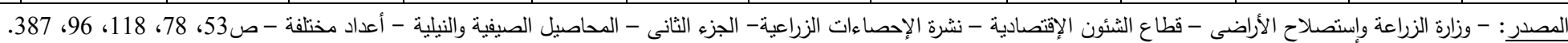

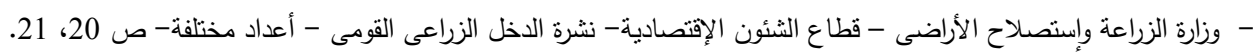

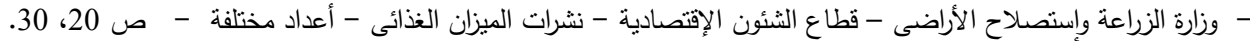


ملحق جدول (8): تطور معدلات الاتجاه الزمنى العام لبعض المتغيرات الاقتصادية لمحاصيل الفاكهة و الحبوب المنتجة للزيوت خلال الفترة (2005-2016).

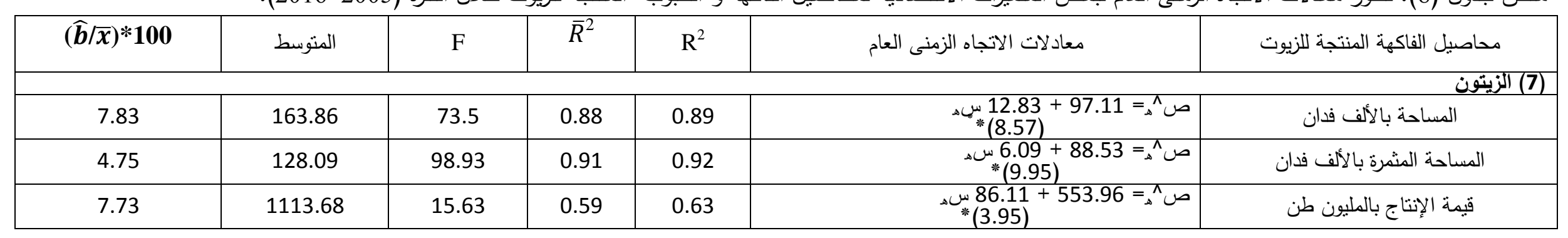

\begin{tabular}{|c|c|c|c|c|c|c|}
\hline$(\widehat{b} / \bar{x})^{* 100}$ & المتوسط & $\mathrm{F}$ & $\bar{R}^{2}$ & $\mathrm{R}^{2}$ & عادلات الاتجاه الزمنى العام & (8) الأرة الثامية وألنيلى البيضاء \\
\hline 1.41 & 2325.76 & 13.88 & 0.54 & 0.58 & 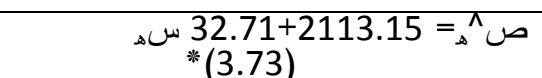 & المساحة بالألف فدان \\
\hline 6.99 & 249.33 & 105.90 & 0.91 & 0.91 & 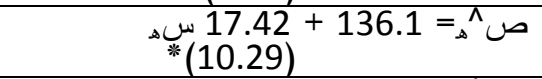 & السعر جنيه/إردب \\
\hline 7.96 & 3316.96 & 10.76 & 0.47 & 0.52 & 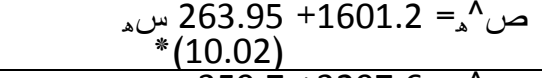 & التكاليف جنيه/فدان \\
\hline 6.38 & 5635.38 & 100.5 & 0.90 & 0.91 & 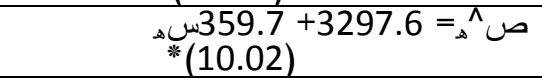 & الإيراد جنيه/فدان \\
\hline
\end{tabular}


أما أربحية الجنيه المنفق فيتم حسابها بقسمة صافى العى العاجي العائد الفدانى للمحصول على التكائل التكاليف الكلية لانتاج

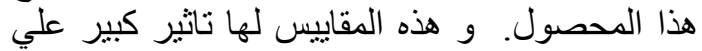

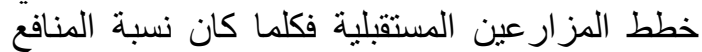

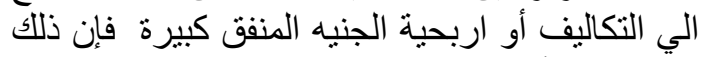

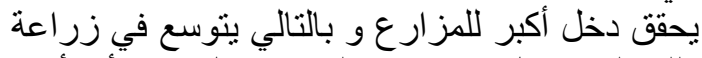

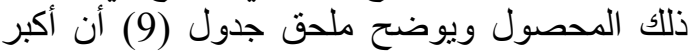
نسبة من المنافع إلى التكاليف الاجمالية كانت للفول التول التبرل

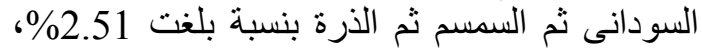
1.78\%، 1.70\% بلى الترتيب و انه كل جنيه منفق يأتى بربح للمز ارع 1.51 ، 0.78 ، 0.62 جنيه على على 0.62

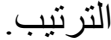

1.5. تظور الانتاج المحلى والعالمى من الزيوت النباتية الغذائية خلاج الفترة (2005-2015)

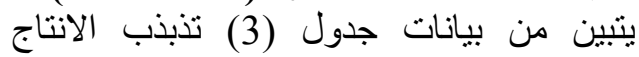

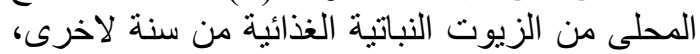

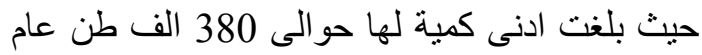
2010 و التى تمثل نسبة بلغت نحو 0.25\% من الانتاج العالمى من الزيوت النباتية الغذائية والتى نئية

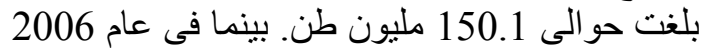

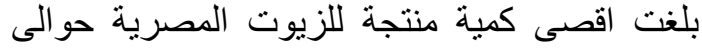

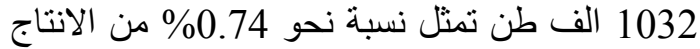

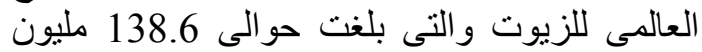
طن. بينما بلغ منوسط الانتاج المصرى من الغرات الزيوت خلال منوسط الفترة (2005-2015) حو الى 651.7 الف طن تمثل نسبة بلغت نحو العالمى من الزيوت و التنى بلغت حو الى نـ 152.6 مليون طن.وتبين تناقص الإنتاج المحلي بمقدار غير معنوي

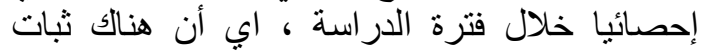

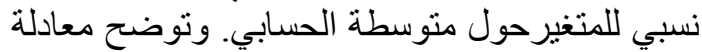
الاتجاه الزمنى العام بجدول (4) تز ايد الانتاج العالمى التئي من الزيوت النباتية الغذائية بمقدارسنوي

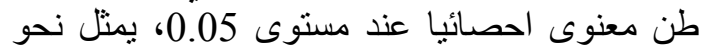

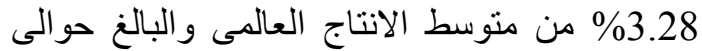
152.6 مليون طن خلال نفس فنرة الدر استة 2.5. الاستهلاك القومى من الزيوت النباتية الغذائية

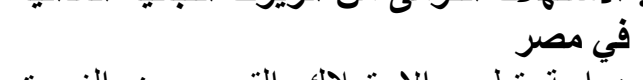
بدراسة تطور الاستهلاك القومي من الزيوت النباتية الغذائية يوضح جدول الإني (5) تذبذب الاستهلاك

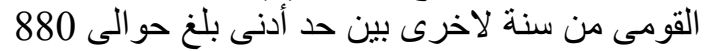

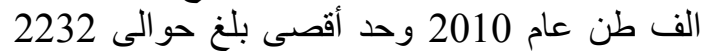
الف طن عام 2013.كما تناقص الإستهلاك القومي خلال متوسط الفترة (2005 -2005 -2015 ) من

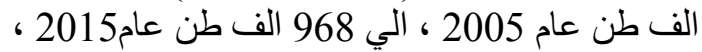
بمعدل تناقص علغ نحو 49.1\%، وقد برجع ذلام ذلك

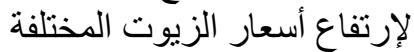

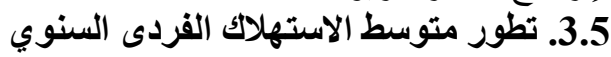

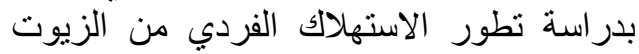

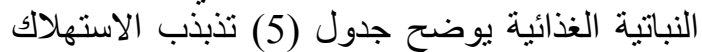

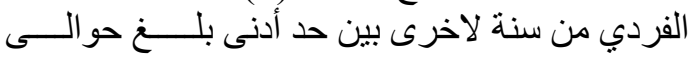

وهي تكلفة أقل من تكلفة الفرصة البديلة لمحاصيل

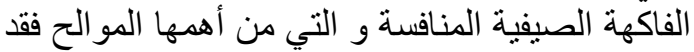

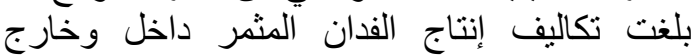

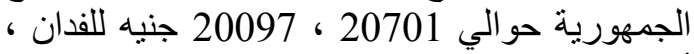

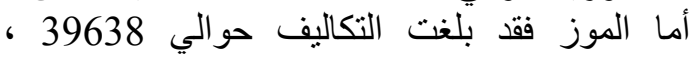
46859 جنيه للفدان ، بينما البرقوق 21556 ، 2343 ،

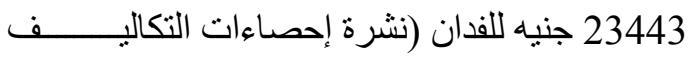

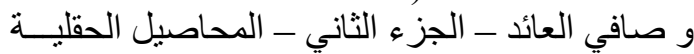

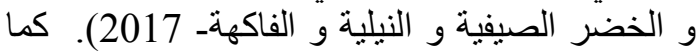
أن محصول الزينون يتحمل الظروف البيئية الصعبة الصية

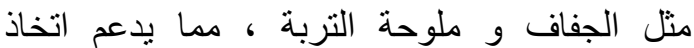
المز ارع لزر اعة المحصول . 8.4.محصول الذرة الثامية النول

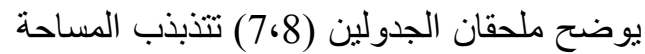

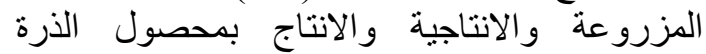

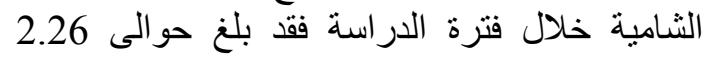

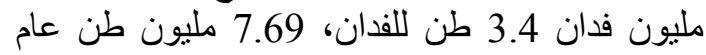
2005، وبلغ 2.45 مليون فدان، 3.420 طن طن/ للفدان،

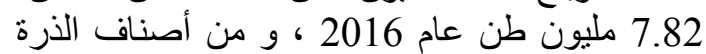

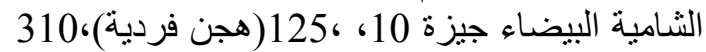

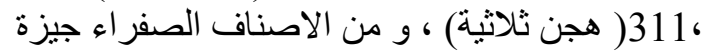

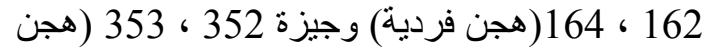

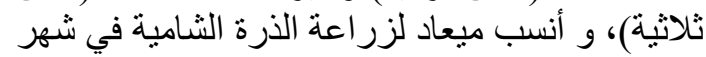

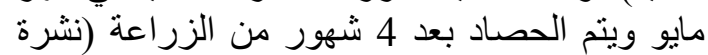

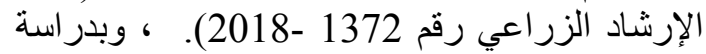

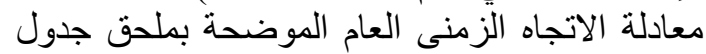

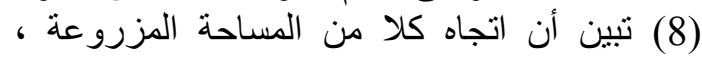

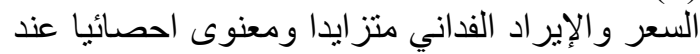

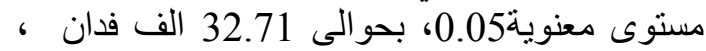
17,42 جنيه للأردب ، 359,7جنيه للفدان سنويا

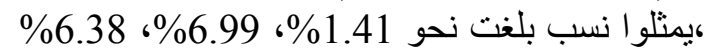
من منوسط الفترة البالغ حو الي 249.33 .76 الفئ الف فدان و249,33 جنيه للأردب ، 5635,38 جنيه للفدان . واخذت التكاليف الكلية للفذان اتجاهاعاما متزايدا

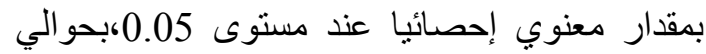

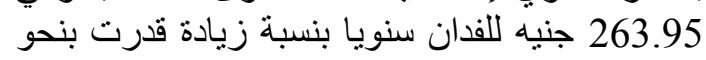
\% 7.96 من منوسط الفترة والبالغة نحو 3316.96 جنيه للفدان. و هي أقل من نكاليف الفرصة الفئرة البديلة

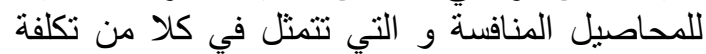
الأرز، القطن 6805 ، ؛ 5070 جنيه للفدان علي نلي 5. بعض المقاييس الاقتصادية المؤثرة على إنتاج المحاصيل الزيتية الغذائية

بدراسة بعض المتغيرات الاقتصادية الفئة التى تؤثر

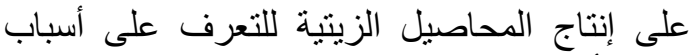

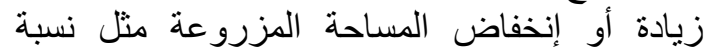

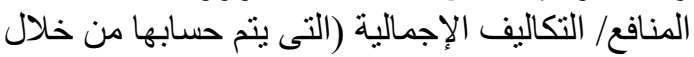

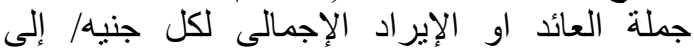

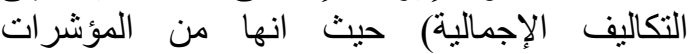
الواضحة على إتخاذ القرارات الانتاجية للمزار النين، 


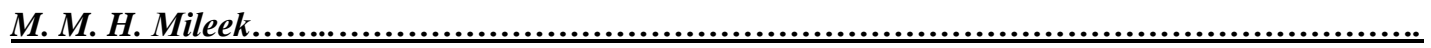

جدول (3): الاهمية النسبية لإتتاج الزيوت النباتية الغذائية المصرية إلى إنتاجها العالمى خلال الفترة (2005-2015).

\begin{tabular}{|c|c|c|c|}
\hline$\%$ & 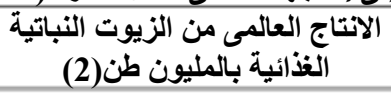 & الانتاج المصرى من الزيوت النبائة بالالف طناية & 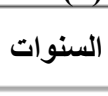 \\
\hline 0.66 & 129.7 & 857 & 2005 \\
\hline 0.74 & 138.6 & 1032 & 2006 \\
\hline 0.33 & 144 & 474 & 2007 \\
\hline 0.29 & 141 & 407 & 2008 \\
\hline 0.28 & 142.1 & 400 & 2009 \\
\hline 0.25 & 150.1 & 380 & 2010 \\
\hline 0.44 & 141.1 & 623 & 2011 \\
\hline 0.47 & 165.2 & 784 & 2012 \\
\hline 0.56 & 163.9 & 919 & 2013 \\
\hline 0.52 & 165.9 & 855 & 2014 \\
\hline 0.22 & 196.5 & 438 & 2015 \\
\hline 0.43 & 152.6 & 651.7 & المتوسط \\
\hline
\end{tabular}

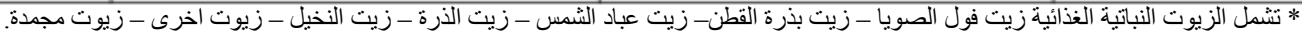

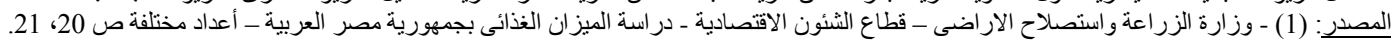
(2) Food and Agricultural organization of the United Nations (F.A.O) production year book. Rome: Italy. Different Voles (2005-2015).

جدول (4): معدلات الاتجاه الزمنى العام لمتغيرات الانتاج المحلى والعالمى للزيوت النباتية الغذائية خلال الفترة (2015-2005).

\begin{tabular}{|c|c|c|c|c|c|c|}
\hline \% معدل التغير & المتوسط & $\mathrm{F}$ & $\mathrm{R}^{-2}$ & $\mathrm{R}^{2}$ & معادلات الاتجاه الزمنى العام & 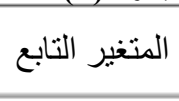 \\
\hline 3.28 & 152.6 & 30.39 & 0.75 & 0.77 & $\begin{array}{c}\text { صه = } 5.003+122.5 \text { سه } \\
\text { سه }\end{array}$ & بالمليون طالمى الانتاج \\
\hline 2.26 & 79.23 & 1031.03 & 0.99 & 0.99 & $\begin{array}{l}\text { ص^ه = } 1.79 \text { ( } 1.48 .44 \text { سهـ } \\
\text { *(32.11) }\end{array}$ & بالمليون نسمة \\
\hline
\end{tabular}

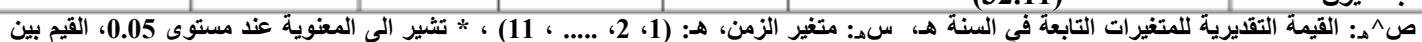

الاقو اس تعبر عن قيمة ت المحسوبة.

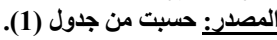

(2) (2) (5) حسبث من جدول جدول)

جذول (5): تطور الإتتاج والاستهلاك القومى والفردى وحجم الفجوة الغذائية والنسبة المئوية للاكتفاء الذاتي من الزيوت النباتية

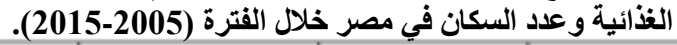

\begin{tabular}{|c|c|c|c|c|c|c|}
\hline 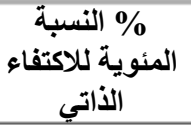 & نالمليون سكان & الاستهملاكية الفجوة الغذائية & متوسط استهلاك & الاستتهلاك الفومى طن & الفومئ الإنتاج & السنوات \\
\hline 45.08 & 70.67 & 1044 & 26.90 & 1901 & 857 & 2005 \\
\hline 46.61 & 73.01 & 1182 & 30.32 & 2214 & 1032 & 2006 \\
\hline 46.84 & 73.66 & 538 & 13.74 & 1012 & 474 & 2007 \\
\hline 42.05 & 75.23 & 561 & 12.87 & 968 & 407 & 2008 \\
\hline 42.64 & 76.82 & 538 & 12.21 & 938 & 400 & 2009 \\
\hline 43.18 & 78.73 & 500 & 11.18 & 880 & 380 & 2010 \\
\hline 36.67 & 80.41 & 1076 & 21.13 & 1699 & 623 & 2011 \\
\hline 42.98 & 82.55 & 1040 & 22.10 & 1824 & 784 & 2012 \\
\hline 41.17 & 84.63 & 1313 & 26.37 & 2232 & 919 & 2013 \\
\hline 42.56 & 86.81 & 1154 & 23.14 & 2009 & 855 & 2014 \\
\hline 45.25 & 88.96 & 530 & 10.88 & 968 & 438 & 2015 \\
\hline 43.18 & 79.23 & 861.45 & 19.17 & 1513.18 & 651.73 & المتوسط \\
\hline
\end{tabular}

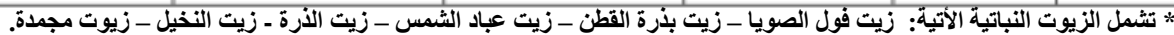

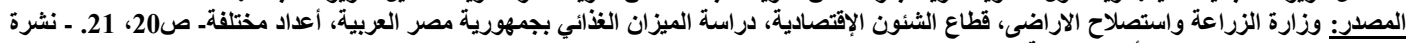

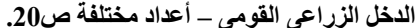


ملحق جدول (9): نسبه المنافع إلى التكاليف الإجمالية، أربحية الجنيه المنفق لمحاصيل الحبوب الزيتية النباتية الغذائية في

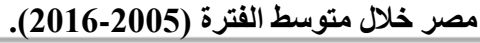

\begin{tabular}{|c|c|c|}
\hline أربحية الجنيه المنفق (صافى العائد الفدانى ٪ & نسبة إجمالي المنافع إلى إجمالى التكاليف & المحصول \\
\hline 0.62 & 1.62 & فول الصويا \\
\hline 1.51 & 2.51 & الفول السودانى \\
\hline 0.78 & 1.78 & السمسم \\
\hline 0.46 & 1.46 & عباد الشمس \\
\hline 0.47 & 1.47 & القطن \\
\hline 0.62 & 1.70 & جنين حبة الذرة \\
\hline
\end{tabular}

فجوة غذائية استهلاكية من الزيوت تسعى الدولة على الإنى

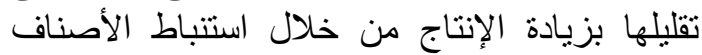

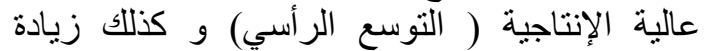

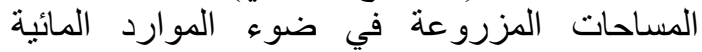

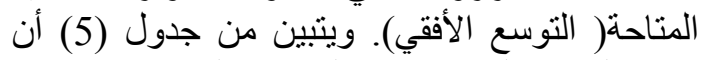

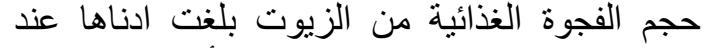

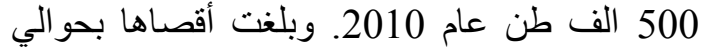
1.3 مليون طن عام 2013. كما يوضن عام جدول تز ايد عدد السكان من حو الى 70.3 ملى مليون عليون نسمة عام 2005، إلى 88.9 مليون نسمة عاد 2015 نياد 2015 بمقدار زيادة 1.7 مليون نسمة سنويا عند مستوي معنوية 0.05. وبلغ معدل التغير السنوي للزياديادة السكانية حوالى 0.26\% من من متوسط الزيادة السنوية البالغة حو الي 79.23 مليون نسمة خلال فتل فترة الدر استة.

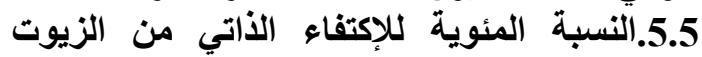
النباتية الغذائية في مصرية لإكناء

تبين من جدول (5) تزايد تللك النسبة زيادة
10.88 كجم /سنة عام 2015 وحد أقصى بلغ حو الى كمأى 30.32كجم /سنة عام 2006، كما تناقص الإستهلاك

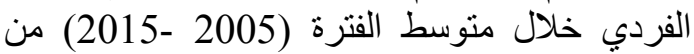

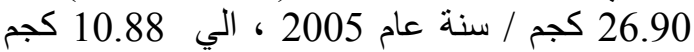
/سنة عام 2015 ، بمعدل تناقص بلّغ نحو 63.61

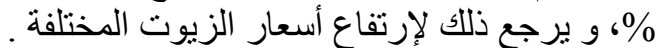
4.5.حجم الفجوة الغذائية من الزيعار الزيوت النباتية الغذائية في مصر الفجوم

يتبين من جدول (4) و ملحق جدول(10) زيادة

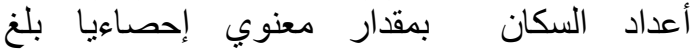
حوالي1.79 مليون نسمة سنويا. وقد بلغ بلغ معدل التغير2.26\% من منوسط عدد السكان خلال فترة متوسط فترة الدراسة و و الذي بلغ حوالي 79.23

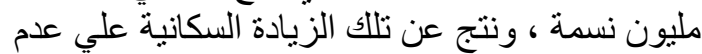

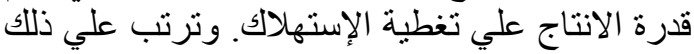

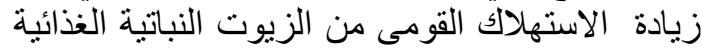
بشكل أكبر من الإنتاج القومى منه لذللك فقد ظهرت

ملحق جدول (10): أهم المتغيرات الاقتصادية المؤثرة على الاستهلاك الفردى للزيوت الغذائية النباتية في مصر خلال متوسط

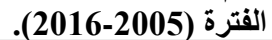

\begin{tabular}{|c|c|c|c|c|c|}
\hline مترسط نصيب & 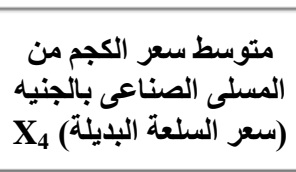 & بتالجزئة للكجم سعر & 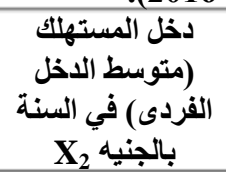 & 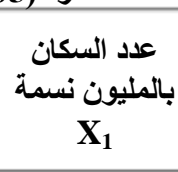 & السنوات \\
\hline 17.7 & 5.3 & 5.4 & 8477.1 & 70.67 & 2005 \\
\hline 19.3 & 5 & 6.5 & 9403.9 & 73.01 & 2006 \\
\hline 10.3 & 5.8 & 6.7 & 10861.5 & 73.66 & 2007 \\
\hline 9.8 & 6.3 & 7.5 & 12776.9 & 75.23 & 2008 \\
\hline 9.4 & 6.3 & 7.9 & 14282.5 & 76.82 & 2009 \\
\hline 8.5 & 6.9 & 8.6 & 16036 & 78.73 & 2010 \\
\hline 6.5 & 7.3 & 9.2 & 1770.5 & 80.41 & 2011 \\
\hline 7 & 7.5 & 9.5 & 1790.7 & 82.55 & 2012 \\
\hline 7.5 & 8.8 & 9.5 & 1865.1 & 84.63 & 2013 \\
\hline 8 & 9 & 10 & 1975.5 & 86.81 & 2014 \\
\hline 4 & 9.2 & 10.8 & 27014.7 & 88.96 & 2015 \\
\hline 2.6 & 9.7 & 11.3 & 17853.5 & 90.04 & 2016 \\
\hline 9.2 & 7.3 & 8.6 & 11175.7 & 80.13 & المتوسط \\
\hline
\end{tabular}

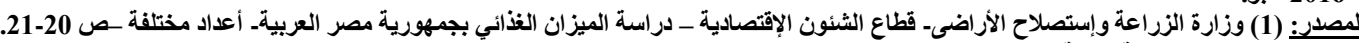

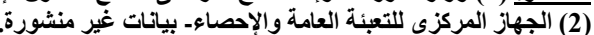

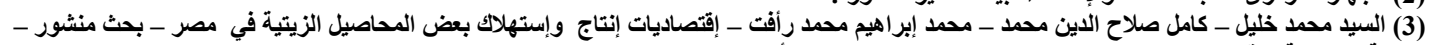

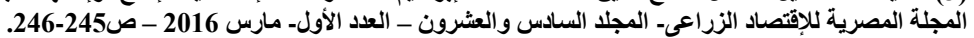


من الزيوت النباتية بنحو 2.45\%، بينما تبين احصائيا

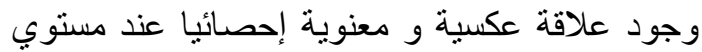

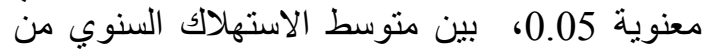
الزيوت النباتية وكلا من متوسط سعر التجزئة بالجنيه

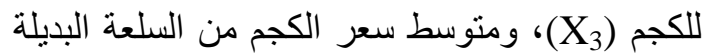

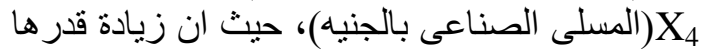

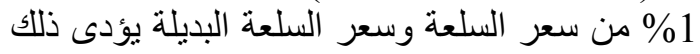

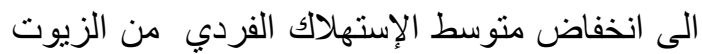

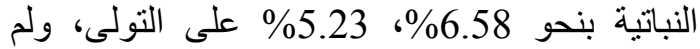

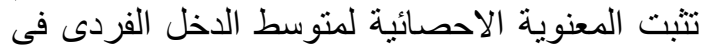

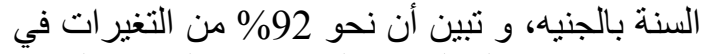

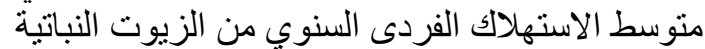
الغذائية نرجع إلى التغيرات الحادثة في المتغير التيرات

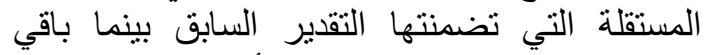
النسبة المئويةٌ نرجع الي عوامل أخري لم تدخل في لئي التقدير.

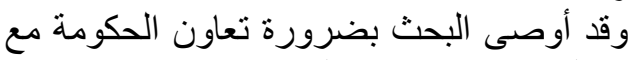

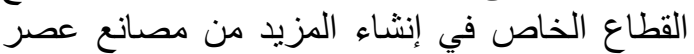
و إستخلاص الزعاع الخيوت النباتية الغذائية لزيادة إنتاجها و

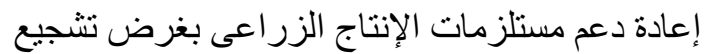
الفلاح على زر اعة محاصيل الزيوت الزئل المختلفة.

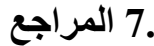

خليل،السيد محمد،محد،كامل صلاح الدين ور أفت،

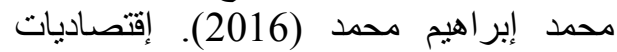
إنتاج وإستهلاك بعض المصن إصنيل الزيتية في مصر . بحث منشور . لمقاع المجلة المصرية

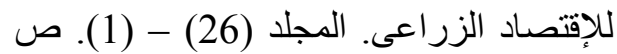
255-239 وزارة الزراعة وإستصلاح الاراضى(2005-

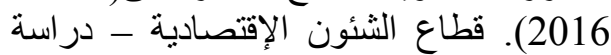
الميزان الغذائي جمهورية مصر الأية العربية

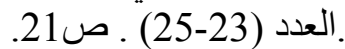
وزارةالزر اعة وإستصلاح الار اضى(23 (2005-2016).

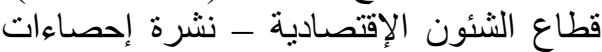

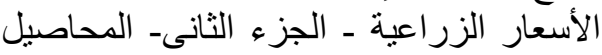

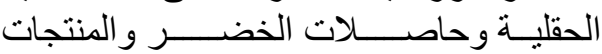
الثنانوية (الصيفية و النيلية) و الفاكهة - أعداد

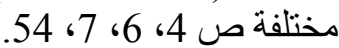
وز ارةالزر اعة و إستصلاح الأر اضى (54. (2005-2016).

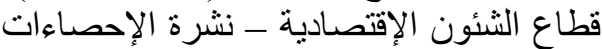
الزر اعية ــ الجزء الثانى ـ المادية المحاصيل الصيفية

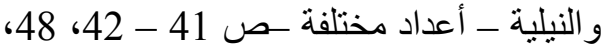
53، 96، 96، 378-377، 389، 390، 390

وزارة الزراعة وإستصلاح الأر اضى (377، (2017). قطاع

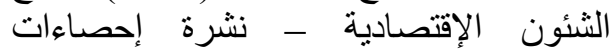

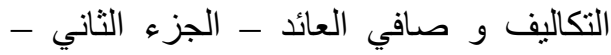
المحاصيل الحقلية و الخضر الصئل الصيفية والنيلية و الفاكهة من ص الفنة 83 الي96.
طفيفة من 45.08\% عام 2005 الي \% 45.25\% عـام بـام

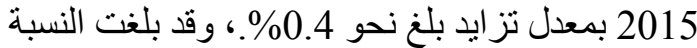

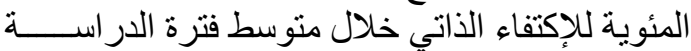

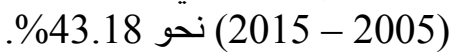

\section{5.دالة الاستهلاك الفردية للزيوت الغذائية النباتية}

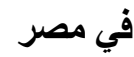

تبين دالة الاستهلاك الفردي مختلف الكميات من

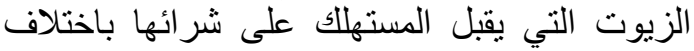

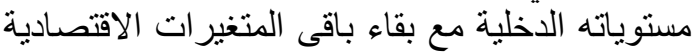

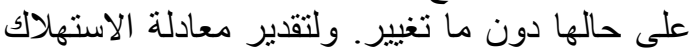

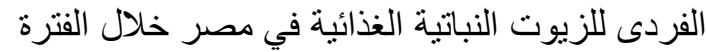

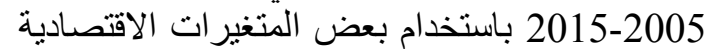

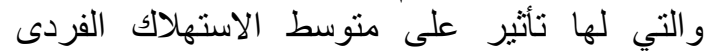
السنوي من الزيوت بالكجم وهى متوسط عدد السكان

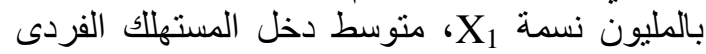
في السنة بالجنيه X2، متوسط سعر التجزئة بالكجم بالجنيه XX، ومتوسط سعر الكجم من السلع البديلة

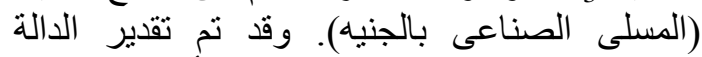

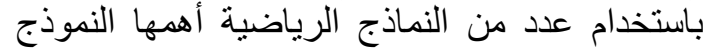

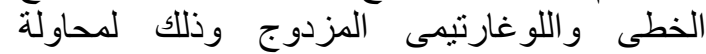

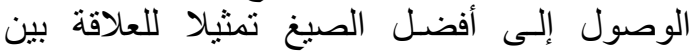
متوسط الاستهلاك الفردى السنوي من الزيوت المئ وأهم

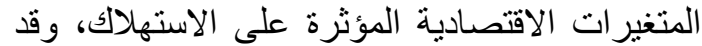

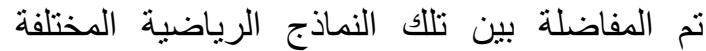

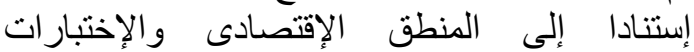

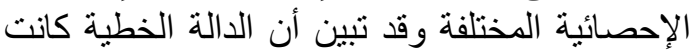

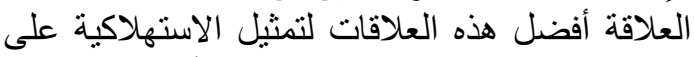

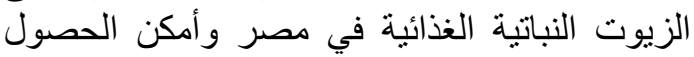
على الاستهلاكية الخطية كما يلى $Y^{\wedge}=-91.63+2.45 X_{1}+0.0001 X_{2}-6.58 X_{3}-5.23 X_{4}$ $(3.25)^{*} \quad(1.28) \quad(-4.21)^{*}(-2.65)^{*}$

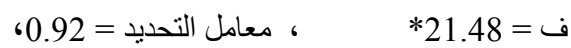
$0.88=0$ معامل التحديد المعدل

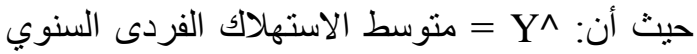

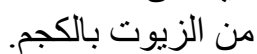
= X X $_{1}$ = X في السنة بالجنيه) = X X $_{3}$

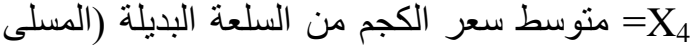
الصناعى) بالجنيه.

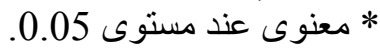

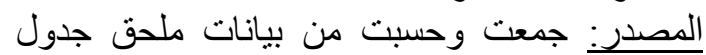

يشير النموذج الخطى السابق إلى أنه قد تأكد

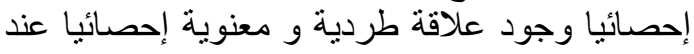

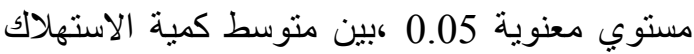

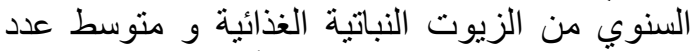

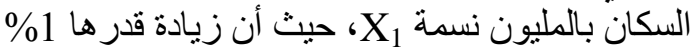
من هذا المتغير يؤدى إلى زيادة متوسط الاستهلاك 


\section{REFERENCE}

Food and Agricultural organization of the United Nations (F.A.O) production year book. Rome: Italy. Different Vole 's (2005-2015).
وز ارةالزر اعة و إستصلاح الار اضى(2015- 2018). مركز البحوث الزراعية_الإدارة المراعية المركزية

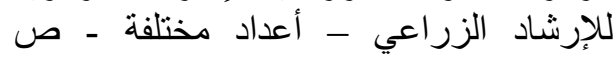
. 10، 8، 3،4، 5،6، 